\title{
Fuzzy Logic Speed Control and Adaptation Mechanism-Based Twelve Sectors DTC to Improve the Performance of a Sensorless Induction Motor Drive
}

\author{
Yassine Zahraoui, Mohamed Akherraz and Sara Elbadaoui \\ Dept. of Electrical Engineering, Mohammed 5 University, \\ Mohammadia School of Engineering, Rabat, Morocco \\ zahraoui.yassin@gmail.com
}

\begin{abstract}
The direct torque control (DTC) was proposed as an alternative to vector control. This strategy uses as a base the direct determination of switching states of the inverter and provides a simpler scheme and less sensitivity to machine parameters. However, the variable switching frequency of DTC engenders high flux and torque ripples which conduct to an acoustical noise and degrade the performance of the control, especially in low-speed regions. In the objective of improving the DTC performance for the induction motor operation, this paper inscribes a modified version of DTC by increasing the number of sectors and inserting a nonlinear fuzzy regulator in the speed regulation loop, in order to ensure a robust control contra different uncertainties and external disturbances. The goal is to achieve a significant reduction of the high ripples of the conventional DTC, which are the major drawbacks. Furthermore, the sensorless control can increase reliability and decrease the cost of the control system. Therefore, a Luenberger observer-based fuzzy adaptation mechanism is implemented to improve speed and flux observation.
\end{abstract}

Keywords: Induction motor drive; twelve sectors DTC; fuzzy logic speed controller; fuzzy adaptation mechanism

\section{Introduction}

The invention of induction motors permanently changed the course of human civilization. This hundred-year-old motor invented by the great scientist Nicola Tesla is the most common machine even today. As a matter of fact, about $50 \%$ of global electric power consumption is due to induction machines. It does not require a permanent magnet, it does not have brushes, commutator rings, or position sensors like other electrical motors. Induction machines are also self-started. The most important advantage is that induction motor speed can be controlled easily by controlling the input voltage frequency. This property makes them an attractive choice for elevators, cranes, even electric cars. Due to the high-speed band of induction machines, electric cars are capable to run with a single-speed transmission. Another interesting property, when the rotor is moved by a prime mover it can also act as a generator. In this case, it is important to make sure that the rotating magnetic field speed is always less than the rotor speed [1].

The vector control, which is known by the field-oriented control (FOC), was developed to overcome the limitation of the scalar control. It was presented in the 1970 s to provide independent control of torque and flux in a similar way to the DC motor with separate excitation. The main disadvantages of FOC are the coordinates transformation which needs the flux angle that cannot be directly measured, additionally, the sensitivity to the variation of the machine parameters, like the stator and the rotor resistances [2]. Another method that guarantees a separated flux and torque control is called direct torque control. It was introduced by Takahashi and Noguchi in the middle of the 1980s in Japan [3]. In contrast to FOC, this control is completely realized in a stationary frame (stator fixed coordinates). On top of that, DTC generates the inverter gating signals directly through a look-up switching table and the use of a modulator is not necessary. It offers an excellent torque response using fewer model

Received: July $2^{\text {nd }}, 2021$. Accepted: August $18^{\text {th }}, 2021$ DOI: 10.15676/ijeei.2021.13.3.1 
parameters than FOC. Due to its simplicity and very fast response, it can be so applicable for high-performance drive applications [4].

Nevertheless, the basic conventional DTC suffers from high flux and torque ripples due to the use of hysteresis controllers, consequently, they cause non-desired ripples in flux and torque. Many modified DTC schemes have been proposed in order to reduce these ripples. Developing a new switching table-based twelve sectors was a very useful solution. This method reduces the high ripples level in spite of its complexity [5]. Besides, increasing the number of sectors to generate the reference control voltages is an efficient technique. This method combines the advantages of both FOC and DTC and eliminates their drawbacks. Considerable studies in the literature mentioned that the increase of the number of the sectors has a slight effect on reducing the high ripples and torque harmonics. In addition, the twelve sectors DTC provides good dynamics in the high and low-speed regions [6].

The linear-proportional-integral-differential (PID) controllers have experienced a wide interest in industrial applications. However, extra extensions should be made to achieve an acceptable behaviour like the output limitation and anti-windup [7]. The development of robust control methods to solve this problem has recently made a big achievement. The nonlinear controllers can offer several advantages compared to linear control schemes. Among the interesting researches in the field of nonlinear control techniques is fuzzy logic control (FLC). FLC is a nonlinear control approach used to obtain a robust control against external perturbations and uncertainties. This algorithm provides good behaviour in steady and dynamic states. In addition, it offers also an exact decoupling between system variables. Due to some limits, such as the sensitivity to modeling errors and disturbances, it has been seldom applied to induction machines [8].

Moreover, sensorless control is another major issue in the control domain. The use of sensors has several disadvantages like high cost, fragility, and low reliability. Furthermore, the physical environment sometimes does not permit the use of sensors. When the sensor is removed, it is called then a sensorless control [9]. Due to the multiple variables and nonlinearity of induction motor dynamics, the observation of the rotor speed and flux without the measurement is still a very challenging subject. Various sensorless approaches have been proposed in the literature. They are classified as opened-loop estimators and closed-loop estimators that are called observers. We mention among them, the determinist adaptive observers [10], stochastic extended Kalman filter (EKF) [11][12], and model reference adaptive system (MRAS) [13].

\section{Induction motor state-space mathematical model}

An induction motor is the most commonly used electrical machine, it is cheaper, rugged, and easier to maintain compared to other alternatives. It has two main parts: stator and rotor, the stator is the stationary part and the rotor is the rotating part. The stator is made by stacking thin slotted highly permeable steel lamination inside a steel or cast-iron frame, winding passes through slots of the stator. When a three-phase AC current passes through it, something very interesting happens. It produces a rotating magnetic field, the speed of rotation of a magnetic field is known as synchronous speed. It is called an induction motor because electricity is induced in the rotor by magnetic induction rather than a direct electrical connection.

Developing new control laws of observation and optimization for the induction machine naturally imposes not to neglect the modeling aspect of this machine. The modeling of AC machines is based mainly on the work of G. Kron, who gave birth to the concept of generalized machines [14]. Park's model is a special case of this concept. It is often used for the synthesis of control laws and estimators. Described by a nonlinear algebra-differential system, Park's model reflects the dynamic behavior of the electrical and electromagnetic modes of the induction machine. It admits several classes of state representations. These model classes depend directly on the control objectives (torque, speed, position), the nature of the power source of the work repository, and the choice of state vector components (flux or currents, stator or rotor) [15]. 
The modeling (Park models) of the induction machine is based on the following traditional assumptions:

1. Perfect symmetry of construction;

2. The magnetic armatures of the stator and the rotor are both concentric cylindrical, separated by a constant air gap, and each provided with a three-phase discharge;

3. Sinusoidal distribution, along the air gap, of stator and rotor magnetic fields;

4. The magnetic circuit is unsaturated and has constant magnetic permeability;

5. The ferromagnetic losses, the skin effect, and the effect of the slots are not taken into consideration.

The mathematical model of a three-phase induction motor in the $\alpha-\beta$ reference frame is:

$$
\left\{\begin{array}{c}
\mathrm{X}=\mathrm{AX}+\mathrm{BU} \\
\mathrm{Y}=\mathbf{C X}
\end{array}\right.
$$

Where $\mathbf{X}, \mathbf{U}$, and $\mathbf{Y}$ are the state, the input, and the output vector respectively:

$\mathrm{X}=\left[\begin{array}{llll}\mathrm{i}_{a s} & \mathrm{i}_{\beta s} & \Phi_{\text {arr }} & \Phi_{\beta \mathrm{r}}\end{array}\right]^{\mathrm{t}} ; \mathrm{U}=\left[\begin{array}{ll}\mathrm{u}_{\mathrm{ass}} & \mathrm{u}_{\beta s}\end{array}\right]^{\mathrm{t}} ; \mathrm{Y}=\left[\begin{array}{ll}\mathrm{i}_{a s} & \mathrm{i}_{\beta s}\end{array}\right]^{\mathrm{t}}$

$i_{\alpha g}$ and $i_{\beta g}$ are the stator current components in the $\alpha-\beta$ reference frame.

$\phi_{\alpha y}$ and $\phi_{\beta y}$ are the rotor flux components in the $\alpha-\beta$ reference frame.

$u_{\alpha g}$ and $u_{\beta g}$ are the stator voltage components in the $\alpha-\beta$ reference frame.

$$
\mathrm{A}=\left[\begin{array}{cccc}
-\mathrm{a}_{1} & \omega_{s} & \mathrm{a}_{2} & \mathrm{a}_{\mathrm{a}} \omega_{\mathrm{r}} \\
-\omega_{s} & -\mathrm{a}_{1} & -\mathrm{a}_{\mathrm{g}} \omega_{\mathrm{r}} & \mathrm{a}_{2} \\
\mathrm{a}_{4} & 0 & -\mathrm{a}_{5} & \omega_{\mathrm{r}} \\
0 & \mathrm{a}_{4} & -\omega_{\mathrm{r}} & -\mathrm{a}_{5}
\end{array}\right] ; \mathrm{B}=\left[\begin{array}{cc}
\frac{1}{\sigma \mathrm{L}_{s}} & 0 \\
0 & \frac{1}{\sigma \mathrm{L}_{s}} \\
0 & 0 \\
0 & 0
\end{array}\right] ; \mathrm{C}=\left[\begin{array}{cccc}
1 & 0 & 0 & 0 \\
0 & 1 & 0 & 0
\end{array}\right]
$$

With: $a_{1}=\frac{R_{s}}{\sigma L_{s}}+\frac{R_{r} L_{m}^{2}}{\sigma L_{s} L_{r}} ; a_{2}=\frac{L_{m}}{\sigma L_{s} L_{r} T_{r}} ; a_{a}=\frac{L_{m}}{\sigma L_{s} L_{r}} ; a_{4}=\frac{L_{m}}{T_{r}} ; a_{5}=\frac{1}{T_{r}} ; T_{r}=\frac{L_{r}}{R_{r}}$.

$R_{g}$ is the stator resistance, $R_{y}$ is the rotor resistance, $L_{g}$ is the stator inductance, $L_{y}$ is the rotor inductance, $L_{m}$ is the mutual inductance, and $T_{r}$ is the rotor time constant.

The state-space mathematical model of the induction motor is shown in Figure 1. The starting-up speed and torque characteristics of the above model are shown in Figure 2.

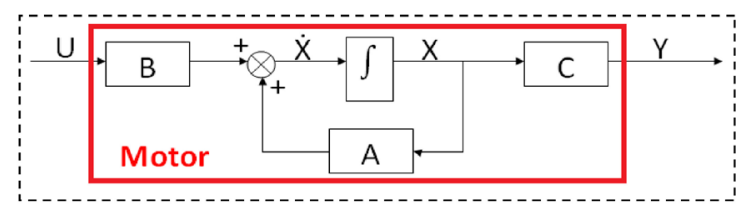

Figure 1. Induction motor state-space mathematical model
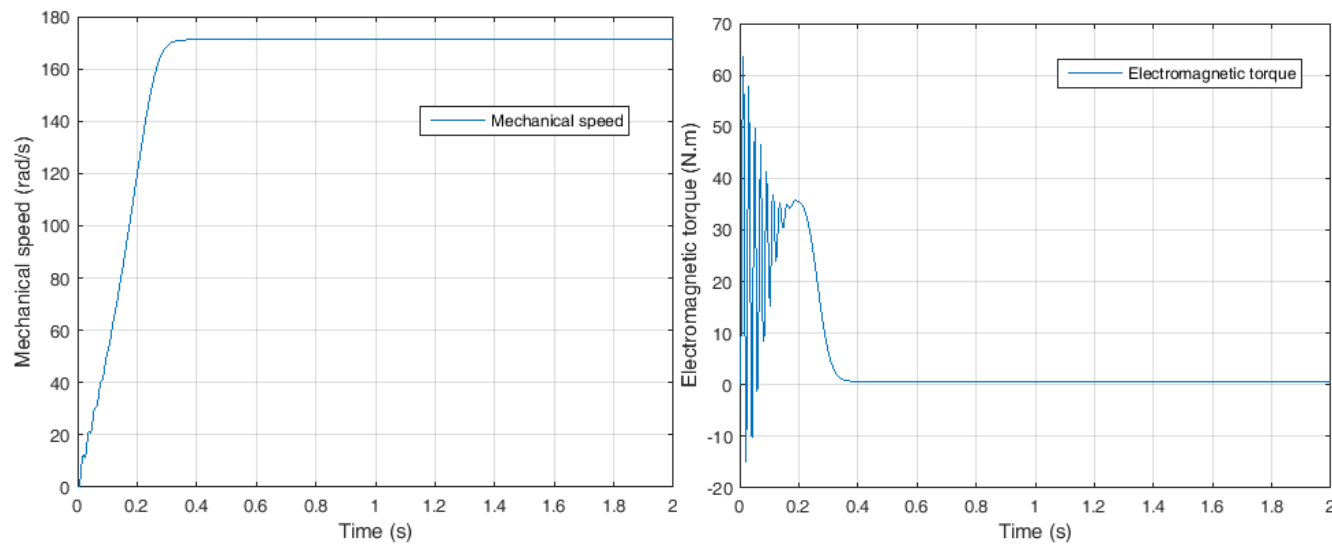

Figure 2. Induction motor starting-up and steady-state 


\section{Conventional direct torque control}

DTC was an alternative to vector control; this technique relies on the direct selection of switching states to control the voltage source inverter (VSI) via a switching table. DTC allows decoupled control of flux and torque in the fixed $\alpha-\beta$ reference frame. It uses a look-up table for the selection of an appropriate voltage vector. The choice of switching states is directly linked to the variation of machine stator flux and torque. Therefore, the selection is made by limiting the amplitudes of flux and torque in two hysteresis bands. These controllers guarantee separate regulation of these two quantities. The inputs to the hysteresis controllers are the flux and torque errors and their outputs determine the appropriate voltage vector for each switching period [16].

\section{A. Stator flux control}

Based on the model of the induction motor in a stationary frame of reference, the stator flux equation can be expressed as follows:

$$
\begin{aligned}
& \frac{d \phi_{s}}{d t}=V_{s}-R_{g} i_{g} \\
& \phi_{g}(t)=\int_{0}^{T_{I}}\left(V_{g}-R_{g} i_{g}\right) d t+\phi_{g}(0)
\end{aligned}
$$

$\phi_{g}(0)$ is the flux vector at instant $\mathrm{t}=0$ and $T_{z}$ is sampling time.

By applying a non-zero vector in the sampling period $T_{z}$, we can neglect the voltage drop of the stator resistance $R_{g} i_{g}$ with respect to $V_{g}$ for the high-speed regions. Then (3) can be written:

$$
\phi_{s}(t) \approx V_{s} T_{z}+\phi_{s}(0)
$$

The relationship between stator voltage and change in stator flux can be established as:

$$
\Delta \phi_{s}=\phi_{s}(t)-\phi_{s}(0)=V_{s} T_{z}
$$

Equation (5) means that the flux can be changed by applying stator voltage for a time $T_{z}$.

The end of the stator flux vector moves in the direction given by the voltage vector and makes a circular path. Figure 3 illustrates the stator flux evolution in the complex plan.

A two-level hysteresis comparator is used for the flux regulation. This makes it easy to drop the end of the flux vector within the boundaries of the two near-radius concentric circles, as shown in Figure 4. The logic outputs of the flux controller are defined as follows:

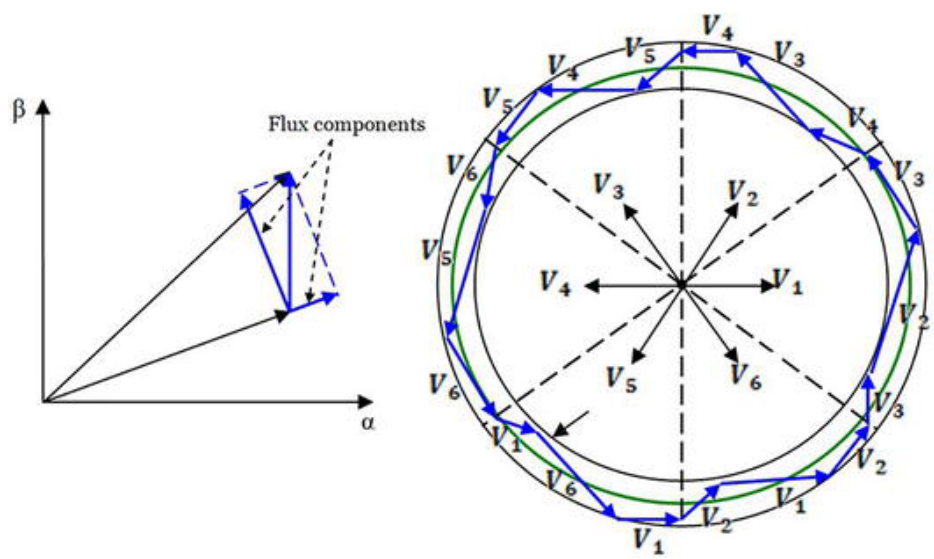

Figure 3. Evolution of the stator flux vector 


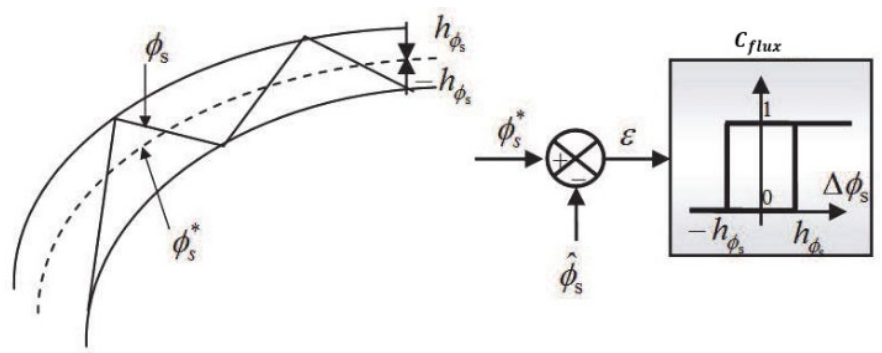

Figure 4. Two-level hysteresis comparator

$$
\left\{\begin{array}{l}
C_{f i u x}=1 \text { if } \Delta \phi_{s}>+h_{\phi_{s}} \\
C_{f l u x}=0 \text { if } \Delta \phi_{s} \leq-h_{\phi_{s}}
\end{array}\right.
$$

$h_{\phi_{s}}$ is hysteresis band of stator flux. The choice of the hysteresis bandwidth $h_{\phi_{s}}$ depends on the inverter switching frequency.

\section{B. Electromagnetic torque control}

During a sampling period, the rotor flux vector is assumed to be invariant. The torque of the induction motor can be expressed in terms of stator and rotor flux vectors, as following:

$$
\begin{aligned}
& T_{E m}=p \frac{M_{s r}}{\sigma L_{s} L_{r}} \phi_{g} \times \phi_{r} \\
& T_{E m}=p \frac{M_{s r}}{\sigma L_{s} L_{r}}\left|\phi_{s} \| \phi_{r}\right| \sin (\delta)
\end{aligned}
$$

Where $\boldsymbol{p}$ is the number of pole pairs, $\phi_{s}$ and $\phi_{r}$ are the vectors of stator and rotor flux. $\delta$ is the angle between the vectors of the stator and rotor fluxes.

From (8), it is clear that the electromagnetic torque is controlled by the magnitudes of the stator and rotor fluxes. If these quantities remain constant, the torque can be controlled by just adjusting the angle $\delta$. Torque regulation can be achieved using a three-level hysteresis comparator as shown in Figure 5.

It allows the motor to be controlled in both directions of rotation. While the two-level comparator can only be used for one direction of rotation. The logic outputs of the torque controller are defined as follows:

$$
\left\{\begin{array}{l}
C_{T_{\mathrm{gmm}}}=+1 \text { if } \Delta \mathrm{T}_{\mathrm{em}}>+h_{T_{\mathrm{gmm}}} \\
C_{T_{\mathrm{gmm}}}=+0 \text { if } \Delta \mathrm{T}_{\mathrm{em}} \leq-h_{T_{\mathrm{gmm}}} \\
C_{T_{\mathrm{gmm}}}=-1 \text { if } \Delta \mathrm{T}_{\mathrm{em}} \leq-h_{T_{\mathrm{gmm}}}
\end{array}\right.
$$

$C_{T_{\mathrm{Rm}}}$ is the hysteresis band of torque.

\section{Stator flux estimation}

The estimation of the stator flux is usually fulfilled by the integration of the back-EMF (electromotive force). The stator flux components can be expressed using stator voltages and currents in the stationary reference frame $(\alpha, \beta)$ by: 


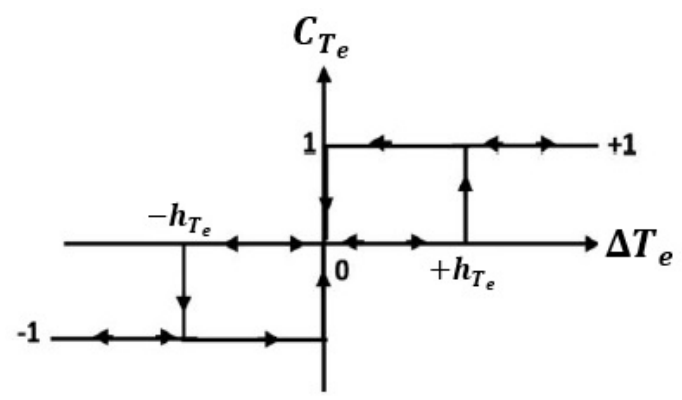

Figure 5. Three-level hysteresis comparator

$$
\left\{\begin{array}{l}
\phi_{s \alpha}=\int_{0}^{5}\left(V_{s \alpha}-R_{g} i_{s E}\right) d t \\
\phi_{s \beta}=\int_{0}^{t}\left(V_{s \beta}-R_{g} i_{s \beta}\right) d t
\end{array}\right.
$$

The stator flux magnitude and angle can then be determined as:

$$
\begin{aligned}
& \left|\phi_{g}\right|=\sqrt{\phi_{s g}^{2}+\phi_{s \beta}^{2}} \\
& \theta_{s}=\tan ^{-1}\left(\frac{\phi_{s g}}{\phi_{s q}}\right)
\end{aligned}
$$

\section{Torque estimation}

The produced induction motor electromagnetic torque can be determined using the cross product of the stator quantities (i.e. stator flux and stator currents). The torque equation is expressed as follows:

$$
T_{e m}=p\left(\phi_{s \alpha} i_{s \beta}-\phi_{s \beta} i_{s \alpha}\right)
$$

\section{E. Switching table construction and control algorithm design}

To maintain decoupled control, two hysteresis comparators receive stator flux and input torque errors. Then, the outputs of the comparators determine the selection of the appropriate voltage vector. However, the choice of voltage vector depends not only on the output of the hysteresis controllers but also on the position of the stator flux vector. Thus, the vector path of the circular stator flux will be divided into six symmetrical sectors.

Where sector $1: \frac{11 \pi}{6} \leq \theta_{g}<\frac{\pi}{6}$; sector $2: \frac{\pi}{6} \leq \theta_{s}<\frac{\pi}{2} ; \ldots ;$ sector $6: \frac{3 \pi}{2} \leq \theta_{g}<\frac{11 \pi}{6}$

While the stator flux vector is located in sector $i$ we have:

- If $V_{i+1}$ is selected, $\phi_{g}$ increases, and $T_{e m}$ increases.

- If $V_{i-1}$ is selected, $\phi_{\sigma}$ increases, and $T_{e m}$ decreases.

- If $V_{i+2}$ is selected, $\phi_{s}$ decreases, and $T_{e m}$ increases.

- If $V_{i-2}$ is selected, $\phi_{g}$ decreases, and $T_{e m}$ decreases.

Figure 6 shows that for each sector the vectors $V_{\mathrm{i}}$ and $V_{\mathrm{i}+\mathrm{a}}$ are not taken into account, as they can both increase or decrease the torque in the same sector depending on the position of the flux vector on the first or the second sector.

If the null vectors $V_{0}$ and $V_{7}$ are selected, the stator flux will stop moving and its amplitude will not change, the electromagnetic torque will decrease, but not as much as when the active voltage vectors are selected. The resulting look-up table for DTC which was proposed by Takahashi is presented in Table 1. 


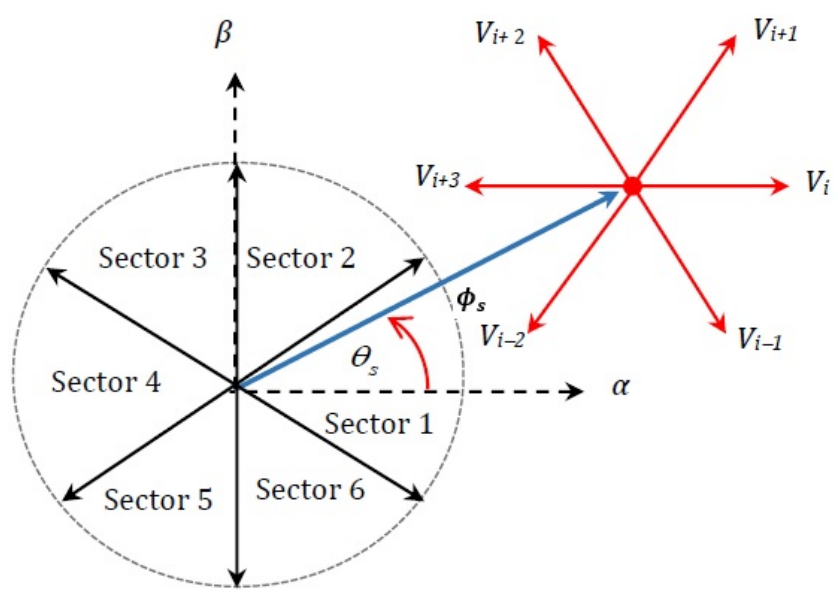

Figure 6. Voltage vector selection when the stator flux vector is located in the sector $\overline{\boldsymbol{i}}$

\section{Twelve sectors DTC strategy for ripples reduction}

In the conventional six-sector DTC, two switching states per sector are not taken into account $\left(V_{i}\right.$ and $\left.V_{i+3}\right)$ because their use causes ambiguity in the torque control. To solve the problem of ambiguity in torque and flux, the position of the stator flux should be divided into 12 sectors instead of 6 as shown in Figure 7. The main advantage of this new distribution is that all six active vectors will be used in the same sector. However, the tangential component of the voltage vector is very low, therefore the torque variation will also be lower. For this, we must introduce the idea of a small torque increase instead of a torque increase [17]. The new partition is given in Figure 8.

Table 1. Switching table for the conventional DTC

\begin{tabular}{|c|c|c|c|c|c|c|c|}
\hline$\Delta \phi_{s}$ & $\Delta T_{e m}$ & $s_{1}$ & $s_{2}$ & $s_{3}$ & $s_{4}$ & $S_{5}$ & $S_{6}$ \\
\hline$C_{f l u x}=1$ & $\begin{array}{l}C_{\text {torque }}=+1 \\
C_{\text {torque }}=+0 \\
C_{\text {torque }}=-1\end{array}$ & $\begin{array}{l}V_{2}(110) \\
V_{7}(111) \\
V_{6}(101)\end{array}$ & $\begin{array}{l}V_{3}(010) \\
V_{0}(000) \\
V_{1}(100)\end{array}$ & $\begin{array}{l}V_{4}(011) \\
V_{7}(111) \\
V_{2}(110)\end{array}$ & $\begin{array}{l}V_{5}(001) \\
V_{0}(000) \\
V_{3}(010)\end{array}$ & $\begin{array}{l}V_{6}(101) \\
V_{7}(111) \\
V_{4}(011)\end{array}$ & $\begin{array}{l}V_{1}(100) \\
V_{0}(000) \\
V_{5}(001)\end{array}$ \\
\hline$C_{f l u x}=0$ & $\begin{array}{l}C_{\text {torque }}=+1 \\
C_{\text {torque }}=+0 \\
C_{\text {torque }}=-1\end{array}$ & $\begin{array}{l}V_{3}(010) \\
V_{0}(000) \\
V_{5}(001)\end{array}$ & $\begin{array}{l}V_{4}(011) \\
V_{7}(111) \\
V_{6}(101)\end{array}$ & $\begin{array}{l}V_{5}(001) \\
V_{0}(000) \\
V_{1}(100)\end{array}$ & $\begin{array}{l}V_{6}(101) \\
V_{7}(111) \\
V_{2}(110)\end{array}$ & $\begin{array}{l}V_{1}(100) \\
V_{0}(000) \\
V_{3}(010)\end{array}$ & $\begin{array}{l}V_{2}(110) \\
V_{7}(111) \\
V_{4}(011)\end{array}$ \\
\hline
\end{tabular}

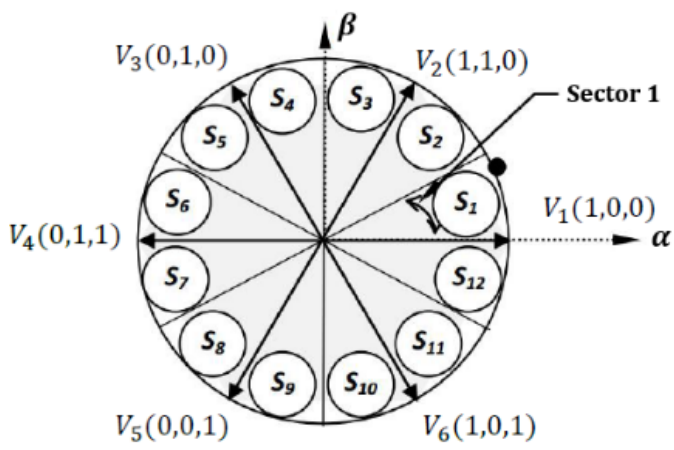

Figure 7. Voltage space vector in twelve sectors partition 


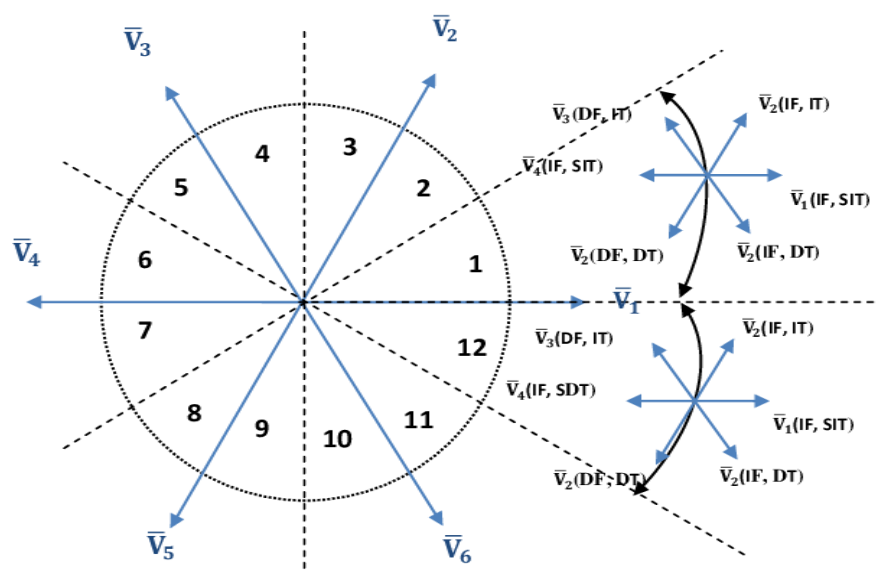

Figure 8 . Voltage space vector in the new partition

To better exploit these voltages, a four-level hysteresis comparator is used for the torque as illustrated in Figure 9. It is possible now to define the small and large variations in torque and flux generated by these same voltage vectors according to their phase shift with respect to zone boundaries. For example, in sector $S_{12}$, if the vector $V_{1}$ is selected it will produce a large increase in flux and a small increase in torque, and $V_{2}$ greatly increases torque and slightly increases flux. In twelve DTC sectors, vector $V_{1}$ produces a large increase in flux and a slight increase in torque for sector 12 . On the contrary, $V_{2}$ produces a large increase in torque and low flux. It can be deduced from this that it is now necessary to define small and large variations in torque. This requires dividing the torque hysteresis band into four parts. Next, a twelve-sector switching table is provided, as shown in Table 2.

Numerous studies have indicated that increasing the number of sectors has a slight effect in reducing high ripples and current harmonics [18][19][20][21]. In addition, the twelve sectors of the DTC provide good dynamics in high and low speed regions.

\section{Speed regulation in 12-sectors DTC strategy}

DTC strategy has the capacity to operate even without a speed regulation loop, so it does not require any information about mechanical rotor speed. This can classify DTC as a speed sensorless strategy for many industrial applications. Otherwise, to achieve an adjustable speed control, a speed controller is necessary to get a speed regulation and to generate the torque of reference. Very often, the proportional-integral (PI) controllers are used for the regulation.

Table 2. Proposed twelve-sector DTC switching table

\begin{tabular}{|c|c|c|c|c|c|c|c|c|c|c|c|c|c|}
\hline$\Delta \phi_{s}$ & $\Delta T_{e m}$ & $S_{1}$ & $S_{2}$ & $S_{3}$ & $S_{4}$ & $S_{5}$ & $S_{6}$ & $S_{7}$ & $S_{8}$ & $S_{9}$ & $S_{10}$ & $S_{11}$ & $S_{12}$ \\
\hline \multirow{4}{*}{1} & +2 & $V_{2}$ & $V_{3}$ & $V_{3}$ & $V_{4}$ & $V_{4}$ & $V_{5}$ & $V_{5}$ & $V_{6}$ & $V_{6}$ & $V_{1}$ & $V_{1}$ & $V_{2}$ \\
& +1 & $V_{2}$ & $V_{2}$ & $V_{3}$ & $V_{3}$ & $V_{4}$ & $V_{4}$ & $V_{5}$ & $V_{5}$ & $V_{6}$ & $V_{6}$ & $V_{1}$ & $V_{1}$ \\
& -1 & $V_{1}$ & $V_{1}$ & $V_{2}$ & $V_{2}$ & $V_{3}$ & $V_{3}$ & $V_{4}$ & $V_{4}$ & $V_{5}$ & $V_{5}$ & $V_{6}$ & $V_{6}$ \\
& -2 & $V_{6}$ & $V_{1}$ & $V_{1}$ & $V_{2}$ & $V_{2}$ & $V_{3}$ & $V_{3}$ & $V_{4}$ & $V_{4}$ & $V_{5}$ & $V_{5}$ & $V_{6}$ \\
\hline \multirow{3}{*}{0} & +2 & $V_{3}$ & $V_{4}$ & $V_{4}$ & $V_{5}$ & $V_{5}$ & $V_{6}$ & $V_{6}$ & $V_{1}$ & $V_{1}$ & $V_{2}$ & $V_{2}$ & $V_{3}$ \\
& +1 & $V_{4}$ & $V_{4}$ & $V_{5}$ & $V_{5}$ & $V_{6}$ & $V_{6}$ & $V_{1}$ & $V_{1}$ & $V_{2}$ & $V_{2}$ & $V_{3}$ & $V_{3}$ \\
& -1 & $V_{5}$ & $V_{5}$ & $V_{6}$ & $V_{6}$ & $V_{1}$ & $V_{1}$ & $V_{2}$ & $V_{2}$ & $V_{3}$ & $V_{3}$ & $V_{4}$ & $V_{4}$ \\
& -2 & $V_{5}$ & $V_{6}$ & $V_{6}$ & $V_{1}$ & $V_{1}$ & $V_{2}$ & $V_{2}$ & $V_{3}$ & $V_{3}$ & $V_{4}$ & $V_{4}$ & $V_{5}$ \\
\hline
\end{tabular}

The fuzzy controller is performed by comparing the speed reference signal to the actual measured speed value. Then the comparison error becomes the input of the controller as shown in Figure 10. Generally, the design of a fuzzy regulator requires the choice of the following parameters: linguistic variables, membership functions, inference method, and defuzzification [22]. With: 


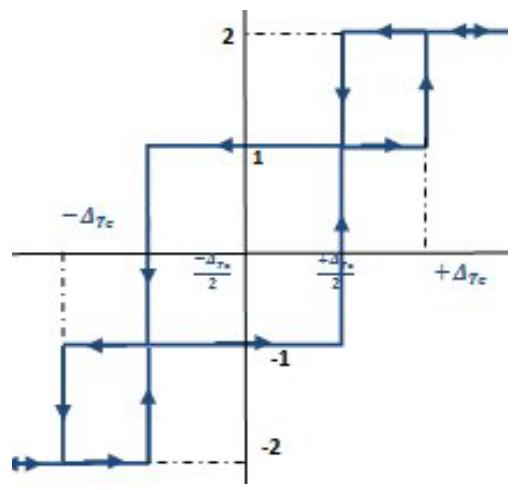

Figure 9. Four-level torque hysteresis comparator

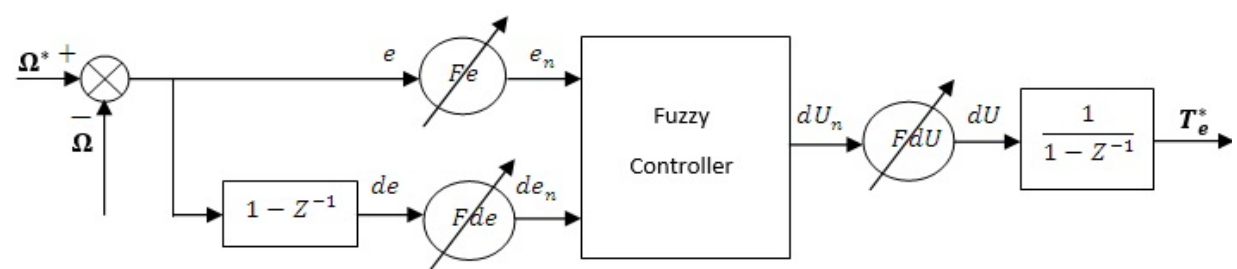

Figure 10. Structure of the speed fuzzy controller

$$
\begin{aligned}
& d e_{k}=\frac{\varepsilon_{k}-\varepsilon_{k-1}}{T_{s}} \\
& T_{e m_{k}}^{*}=T_{e m k-1}^{*}-d U_{k}
\end{aligned}
$$

Symmetrical triangular membership functions with 7 fuzzy sets are used for the input and output variables as shown in Figures. 12 and 13. The linguistic variables are defined as follows: NB (Negative Big), NM (Negative Medium), NS (Negative Small), Z (Zero), PS (Positive Small), PM (Positive Medium), PB (Positive Big).

The fuzzy rules, used to determine the regulator's output variable, are deduced from a table called the inference table. In this case, $7 \times 7=49$ rules as shown in Table 3 . This inference matrix is established on the basis of a perfect knowledge of the behaviour of the system to be adjusted, as well as knowledge of the objective of the control to be achieved [23].

The method of inference used in this work is Mamdani's method whose fuzzy rule which connects the output with the inputs is of the kind: if $e_{n}$ is NS and $d e_{n}$ is NM so $d U_{n}$ is NB.
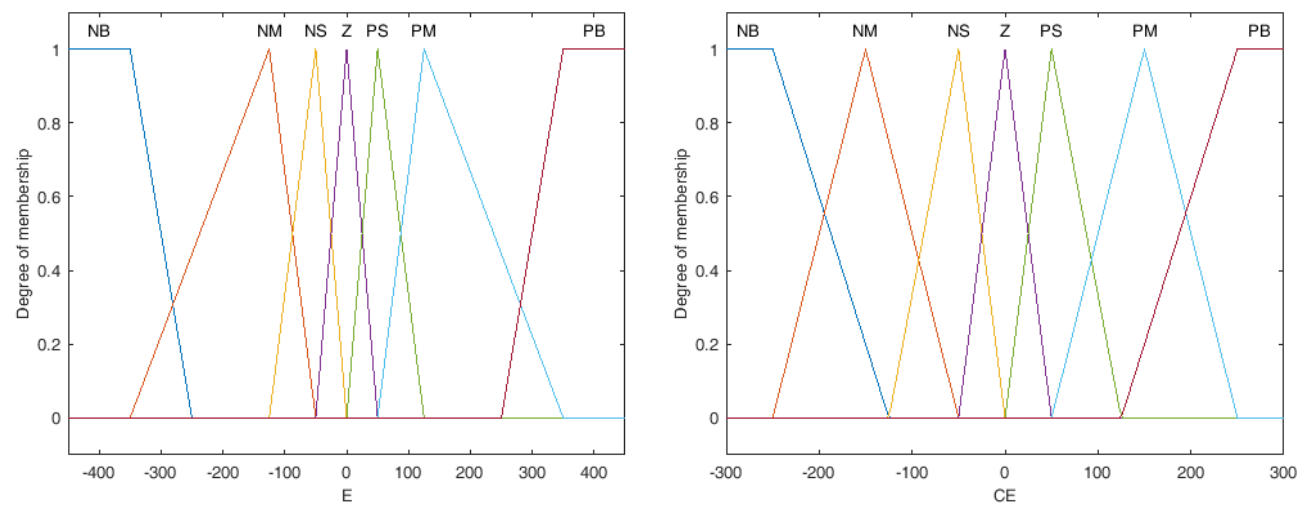

Figure 11. Membership function of error $\boldsymbol{e}_{\mathrm{n}}$ and error variation $d e_{\mathrm{n}}$ 
Once the fuzzy output is calculated, it must be transformed into a physical value, this is the role of the defuzzification interface. In this work, the center of gravity method is chosen as a defuzzification criterion because it allows to express analytically the output of the fuzzy regulator, to simplify its implementation and to reduce the calculation time [24][25]. In this case, the abscissa of the center of gravity corresponding to the output of the fuzzy regulator of the Mamdani type is given by the following relation:

$$
d U_{n}=\frac{\int x \mu_{R}(x) d x}{\int \mu_{R}(x) d x}
$$
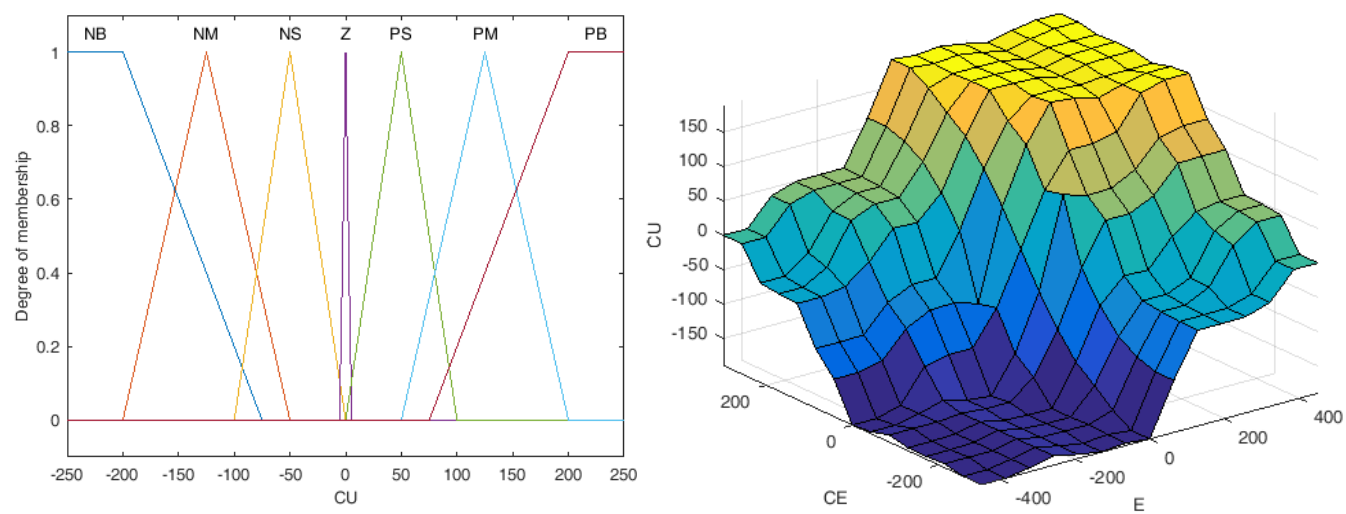

Figure 12. Membership function of output $d U_{\mathrm{m}}$ and surface

Table 3. Inference matrices

\begin{tabular}{|c|c|c|c|c|c|c|c|}
\hline e/ce & NB & NM & NS & Z & PS & PM & PB \\
\hline PB & Z & PS & PM & PB & PB & PB & PB \\
\hline PM & NS & Z & PS & PM & PB & PB & PB \\
\hline PS & NM & NS & $Z$ & PS & PM & PB & PB \\
\hline Z & NB & NM & NS & Z & PS & PM & PB \\
\hline NS & NB & NB & NM & NS & Z & PS & PM \\
\hline NM & NB & NB & NB & NM & NS & Z & PS \\
\hline NB & NB & NB & NB & NB & NM & NS & Z \\
\hline
\end{tabular}

\section{Fuzzy adaptive Luenberger observer for stator flux and speed estimation}

The adaptive observer is a deterministic type of observer based on a deterministic model of the system. In this work, the adaptive Luenberger observer (ALO) is used to estimate the stator flux components and the rotor speed by including an adaptive mechanism based on the Lyapunov theory and fuzzy regulation. In general, the equations of the ALO can be expressed as follow:

$$
\left\{\begin{array}{c}
\widehat{\mathrm{X}}=\mathrm{AX}+\mathrm{BU}+\mathrm{L}(\mathrm{Y}-\widehat{\mathrm{Y}}) \\
\widehat{\mathrm{Y}}=\mathrm{C} \widehat{\mathrm{X}}
\end{array}\right.
$$

The symbol $\wedge$ denotes the estimated value and $\mathrm{L}$ is the observer gain matrix. The goal of this observer is to make the estimated state converge towards its true value. The observer error can be written:

$$
e=X-\hat{X}
$$


We can also define the error dynamic of the observer as a function of the gain matrix:

$$
\dot{e}=(A-L C)_{e}
$$

The dynamics of the observer is given by the following characteristic equation:

$$
\operatorname{det}(s I-(A-L C))=0
$$

The gains of the observer matrix $\mathrm{L}$ are chosen by the conventional pole placement method. The general rule is to choose the poles of the observer five to six times faster than those of the system to be observed.

The observer's gain matrix $L_{\text {m }}$ must ensure the stability and the dynamic of observation so that (A-LC) is asymptotically stable [26]. Therefore, this matrix must be chosen in such a way that all the eigenvalues of (A-LC) have negative real parts. To ensure the stability of the entire speed range, the classic procedure is to choose the observer's poles proportional to the poles of the motor. Denoting by $k$, the unique proportionality constant of usually small value $(k \geqslant 1)$. If the poles of the induction motor are given by $\mathrm{p}_{\mathrm{IM}}$, the poles of the $\mathrm{p}_{\mathrm{LO}}$ observer are selected by the following expression:

$$
p_{L O}=k \times p_{T M}
$$

We define the characteristic equation of the open loop system $\operatorname{det}\left[p_{I M} I-A\right]=0$ by:

$$
p_{I M}^{2}+\left(\gamma I+\frac{I}{T_{y}}-\omega_{y} J\right) p_{I M}+\left(\gamma I-\mu \frac{M}{T_{y}} I\right)\left(\frac{I}{T_{y}}-\omega_{y} J\right)=0
$$

The dynamic of the observer is defined in a closed-loop according to the following characteristic equation:

$$
p_{L O}^{2}+\left(L_{1}+\gamma I+\frac{I}{T_{y}}-\omega_{\gamma} J\right) p_{L O}+\left[\left(\gamma I-\mu \frac{M}{T_{Y}} I\right)-\left(L_{2}+\mu L\right)\right]\left(\frac{I}{T_{y}}-\omega_{\gamma} J\right)=0
$$

$L_{1}$ and $L_{2}$ are the gain matrix components.

By substituting (20) in (22) and identifying the two expressions $\mathrm{k}^{2} \times(21)$ and (22), we find the coefficients of the observer gain matrix:

$$
\begin{aligned}
& l_{1}=(k-1)\left(\gamma+\frac{1}{T_{r}}\right) \\
& l_{2}=-\hat{\omega}_{y}(k-1) \\
& l_{a}=\left(k^{2}-1\right)\left(\frac{\gamma}{\mu}-\frac{M}{T_{r}}\right)+\frac{(k-1)}{\mu}\left(\gamma+\frac{1}{T_{r}}\right) \\
& l_{4}=-\hat{\omega}_{r} \frac{(k-1)}{\mu}
\end{aligned}
$$

The mechanism of adaptation speed is deduced by the Lyapunov theory. The estimation error of the stator current and rotor flux, which is the difference between the observer and the model of the motor, is given by:

$$
\dot{\mathrm{e}}=(\mathrm{A}-\mathrm{LC}) \mathrm{e}+\Delta \mathrm{A} \widehat{\mathrm{X}}
$$

The state error matrix $\Delta A$ is expressed by:

$$
\Delta A=A-\widehat{A}=\left[\begin{array}{cccc}
0 & 0 & 0 & K \Delta \omega_{r} \\
0 & 0 & -\mathrm{K} \Delta \omega_{\mathrm{r}} & 0 \\
0 & 0 & 0 & -\Delta \omega_{\mathrm{r}} \\
0 & 0 & \Delta \omega_{\mathrm{r}} & 0
\end{array}\right]
$$

With: $\Delta \omega_{\mathrm{r}}=\omega_{\mathrm{r}}-\widehat{\omega}_{\mathrm{r}}$

Definition: We consider the following Lyapunov function:

$$
V=e^{t} e+\frac{\left(\Delta \omega_{\mathrm{r}}\right)^{2}}{x}
$$


Where $\lambda$ is a positive coefficient. Its derivative is given as follow:

$$
V=e^{t}\left[(A-L C)^{t}+(A-L C)\right]_{e}-2 K \Delta \omega_{r}\left(e_{i s \alpha} \widehat{\phi}_{r \beta}-e_{i s \beta} \hat{\phi}_{r \alpha}\right)+\frac{2}{\lambda} \Delta \omega_{r} \hat{\omega}_{r}
$$

With $\hat{\omega}_{y}$ is the estimated rotor speed.

The adaptation law for the estimation of the rotor speed can be deduced by the equality between the second and third terms of (26):

$$
\hat{\omega}_{\mathrm{r}}=\int \lambda \mathrm{K}\left(\mathrm{e}_{\mathrm{is \alpha}} \widehat{\phi}_{\mathrm{r} \beta}-\mathrm{e}_{\mathrm{is \beta}} \widehat{\phi}_{\mathrm{ra}}\right) \mathrm{dt}
$$

Remark: $k_{1}$ is a positive coefficient obtained by the pole placement approach; a wise choice was made for its value in order to guarantee a fast response. Fuzzy logic control in the adaptation mechanism replaces conventional control and gives robust performance against parameter variation and machine saturation [27].

The state-space mathematical model of the adaptive observer is illustrated in Figure 13.

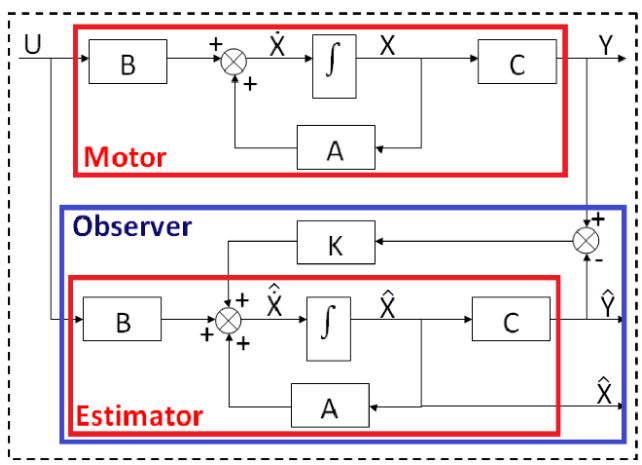

Figure 13. The observer state space mathematical model

The diagram of the overall control-based twelve sectors DTC strategy and fuzzy speed controller is shown in Figure 14.

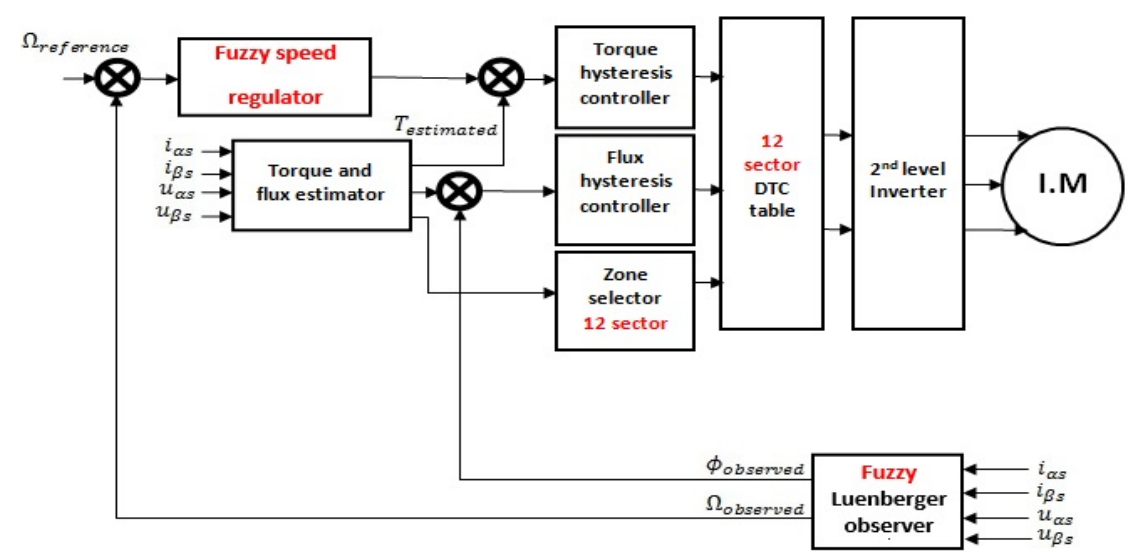

Figure 14. The proposed control scheme

\section{Results and discussion}

The modified DTC strategy associated with the fuzzy speed controller has been simulated by MATLAB/Simulink. A comparative study between the conventional and the improved technique is presented in detail. The simulation has been conducted for a 3 -phase $\mathbf{3 k W}$ squirrel-cage induction motor with characteristics given in the Appendix. A special analysis using the Fast Fourier Transform (FFT) is necessary to detect the flux and torque harmonic 
order. The first test in Figure 15 presents the starting up of the induction motor according to a low-speed step reference of $10 \mathrm{rad} / \mathrm{s}$. A load of $10 \mathrm{N.m}$ is applied at $t=0.6 \mathrm{~s}$ and removed at $t=1.6 s$.
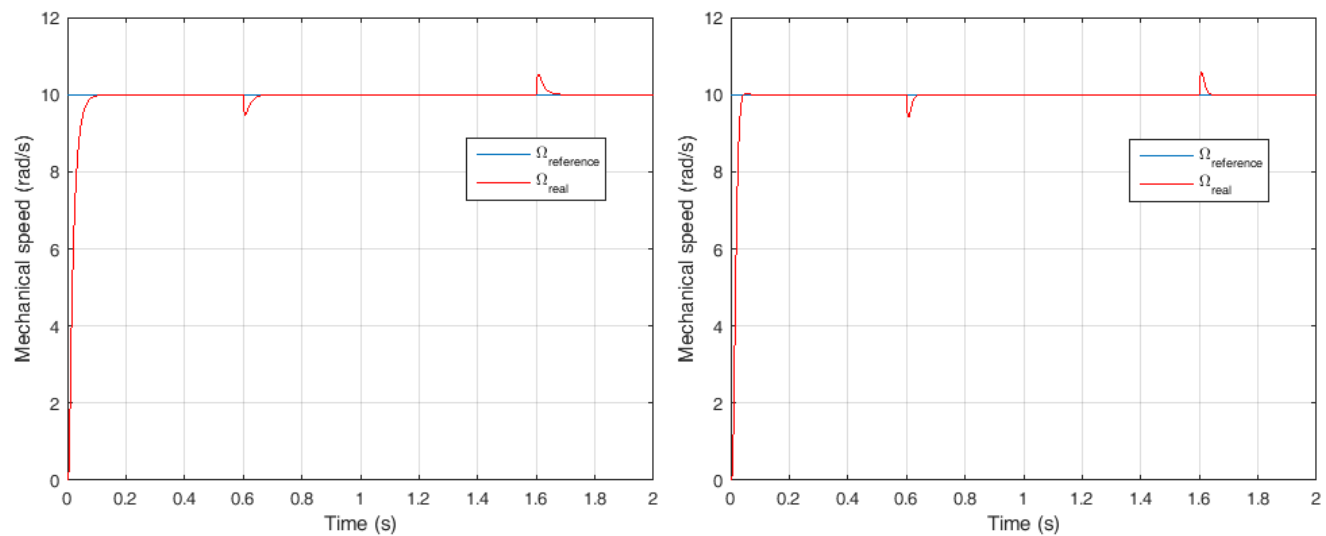

(a) Conventional DTC: mechanical speed

(b) Modified DTC: mechanical speed
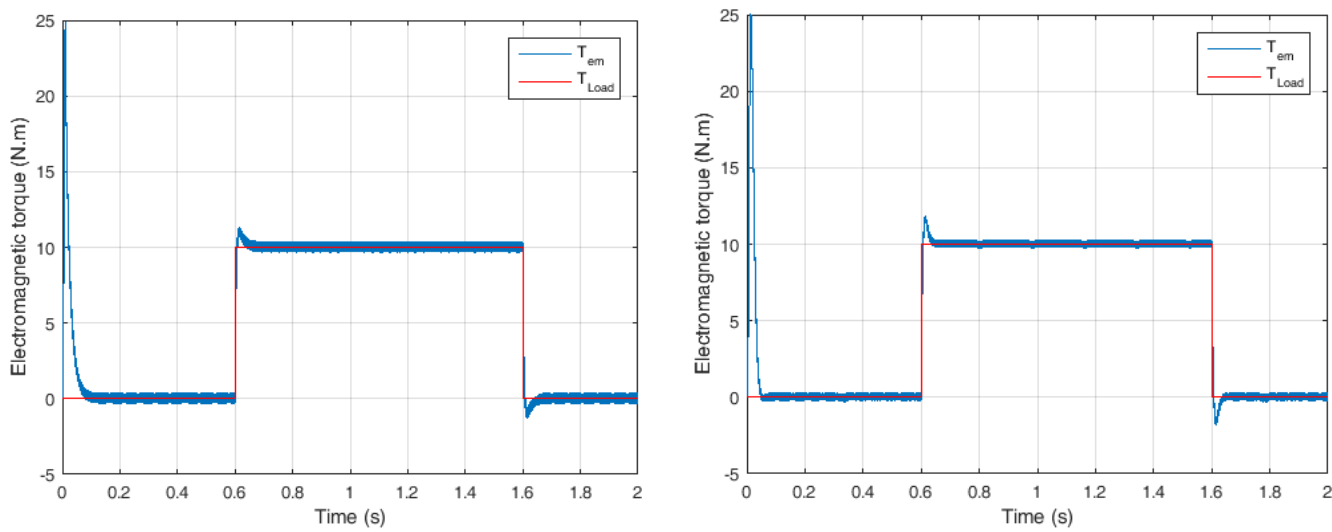

(c) Conventional DTC: electromagnetic torque

(d) Modified DTC: electromagnetic torque
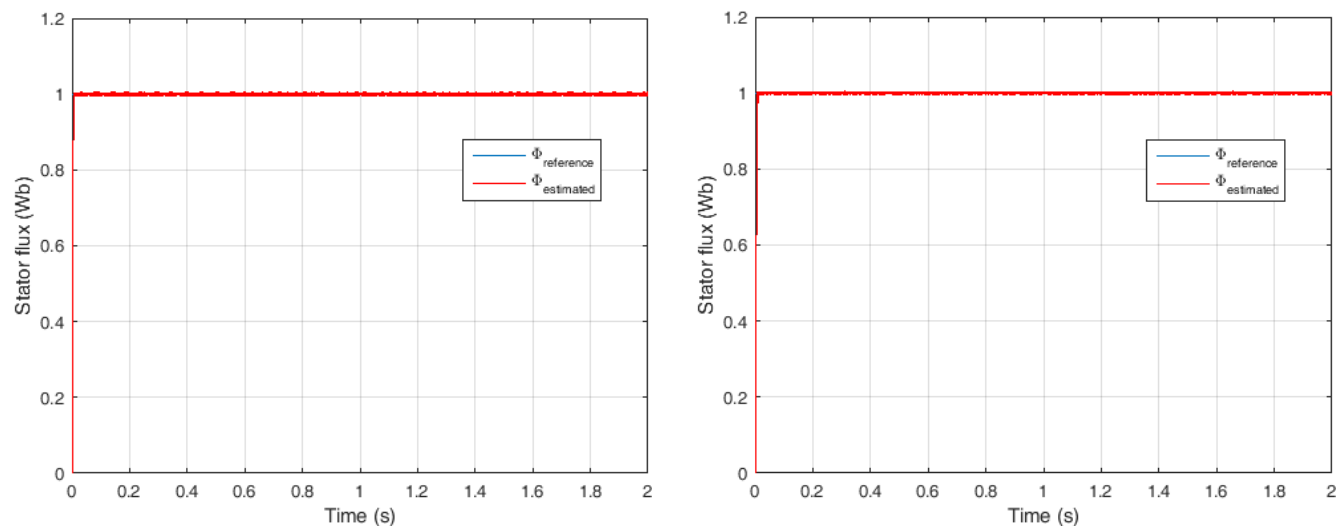

(e) Conventional DTC: stator flux

(f) Modified DTC: stator flux 

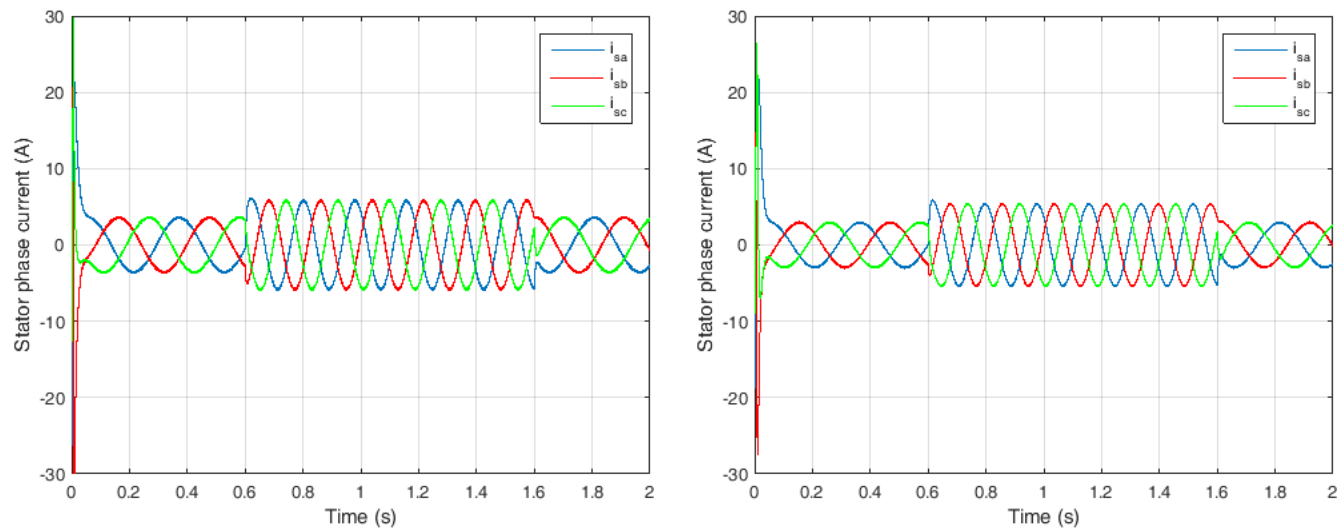

(g) Conventional DTC: stator phase currents

(h) Modified DTC: stator phase currents
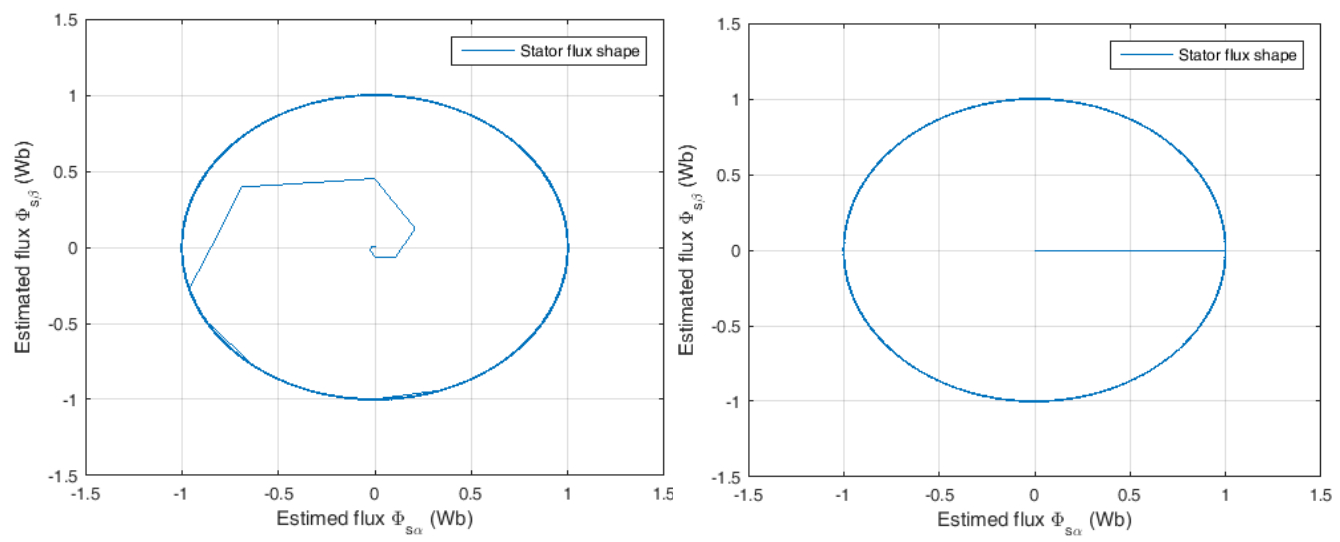

(i) Conventional DTC: flux circular trajectory

(j) Modified DTC: flux circular trajectory
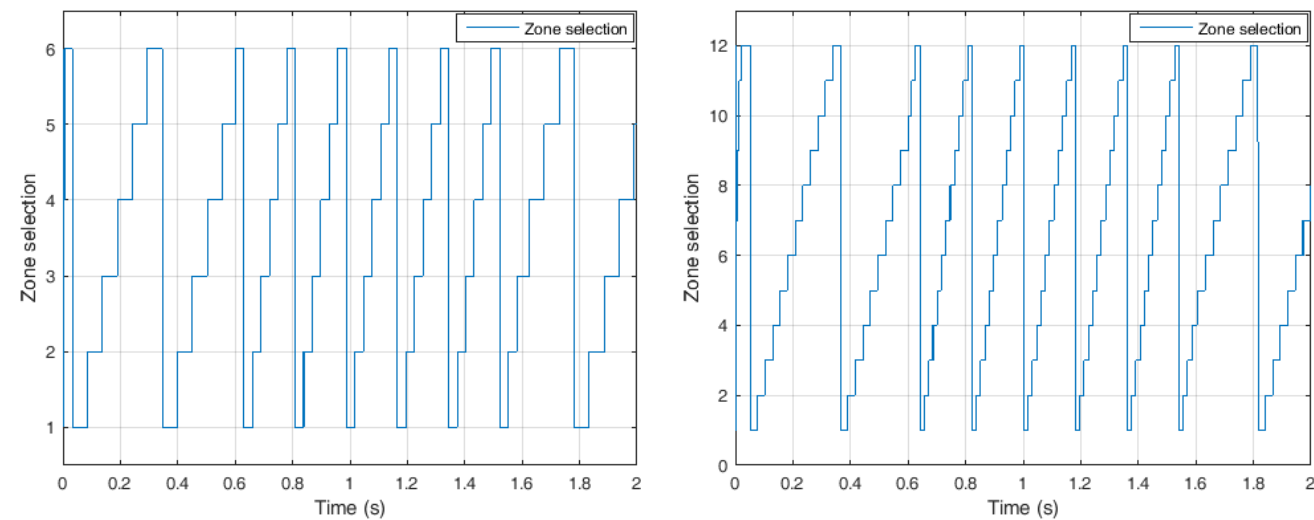

(k) Conventional DTC: sector selection

(l) Modified DTC: sector selection

Figure 15. Low-speed performance improvement

The simulation results show that both techniques have good dynamics at starting up. Figure 15 (a) and (b) shows that the speed regulation loop rejects the applied load quickly. The 
modified DTC has a faster response time compared to the conventional DTC. The transient response is improved, the fuzzy speed controller is robust than the PI controller.

The conventional DTC in Figure 15 (c) shows a chopped sinusoid waveform of torque which indicates the high harmonics level, while the modified DTC in Figure 15 (d) shows a smoother waveform. It can be justified in the next Figure 16 where the modified DTC has a lower THD level, $\mathbf{3 3 . 5 0 \%}$ compared to $\mathbf{4 2 . 3 3 \%}$ for the conventional DTC.

The stator flux in Figure 15 (e) shows an acceptable waveform but high ripples level. The modified DTC in Figure 15 (f) shows reducer flux ripples than the conventional DTC, 91.36\% compared to $\mathbf{1 2 3 . 3 9 \%}$ for the conventional DTC.

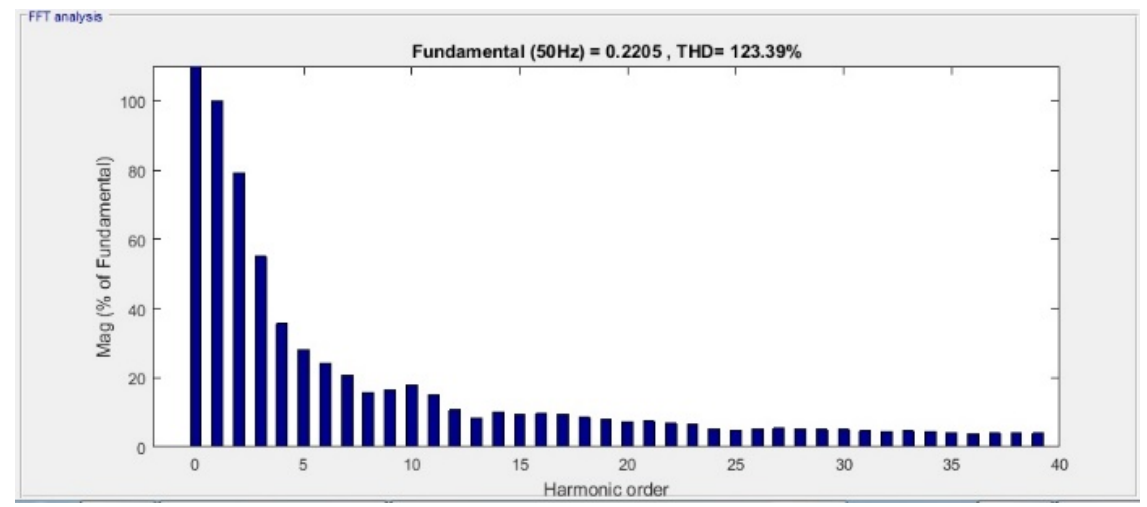

(a). Conventional DTC: THD of stator flux

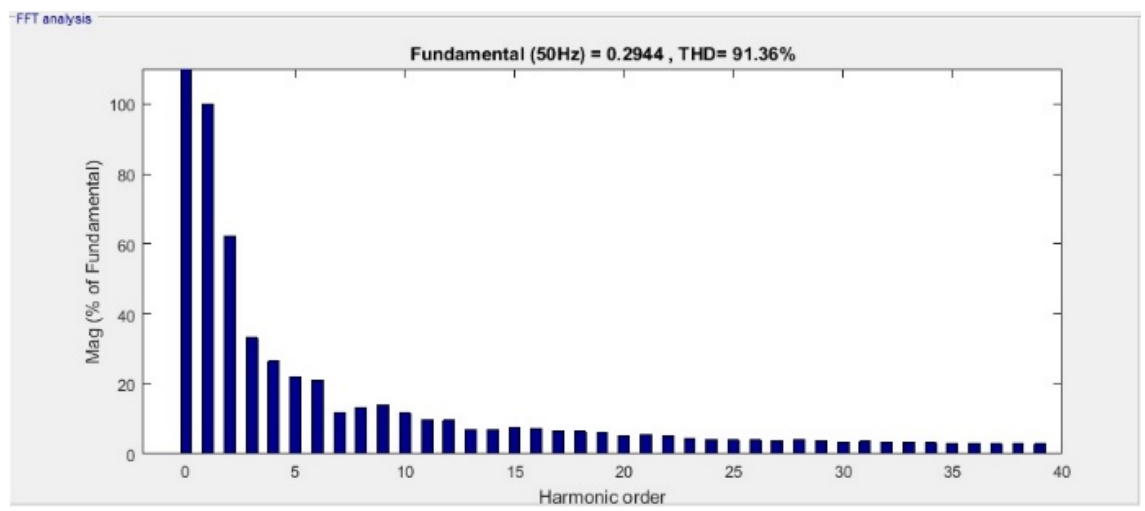

(b). Modified DTC: THD of stator flux

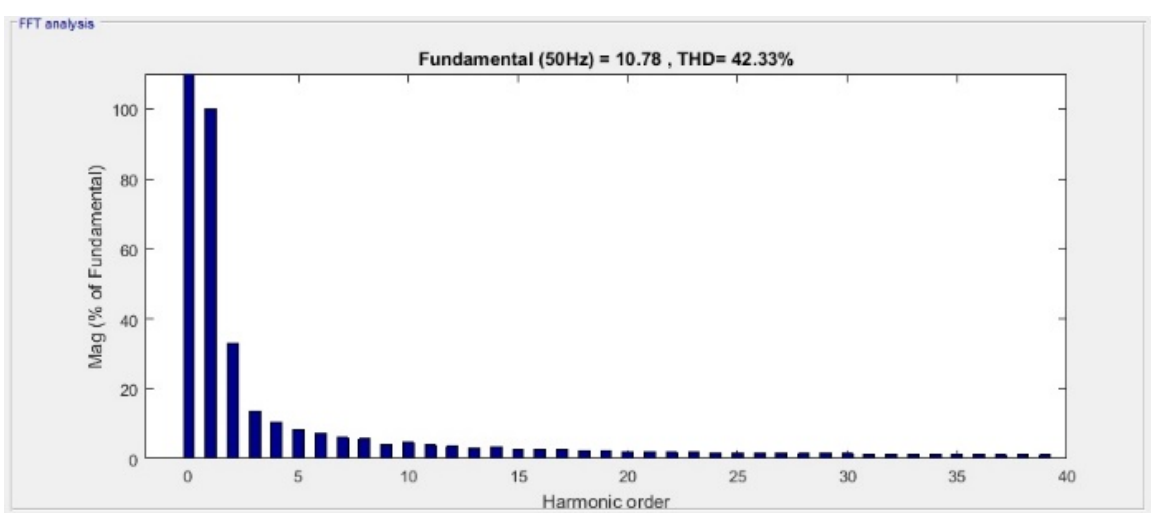

(c). Conventional DTC: THD of electromagnetic torque 


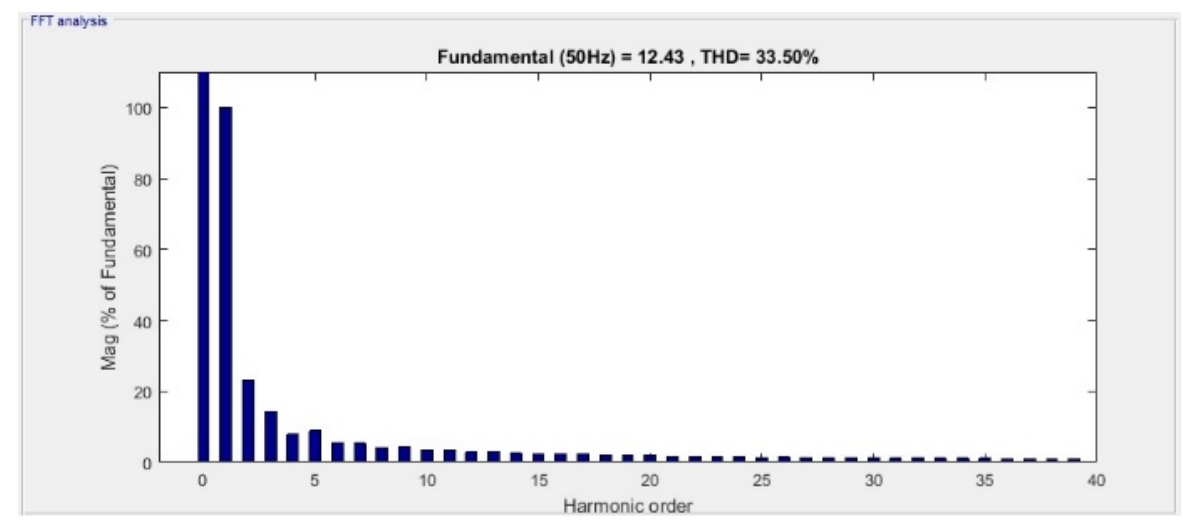

(d). Modified DTC: THD of electromagnetic torque

Figure 16. Torque and flux THD improvement

The second test in Figure 17 presents the starting up of the induction motor according to a high-speed step reference of $120 \mathrm{rad} / \mathrm{s}$. A load of $10 \mathrm{N.m}$ is applied at $t=0.6 \mathrm{~s}$ and removed at $\boldsymbol{t}=\mathbf{1 . 6 s}$.
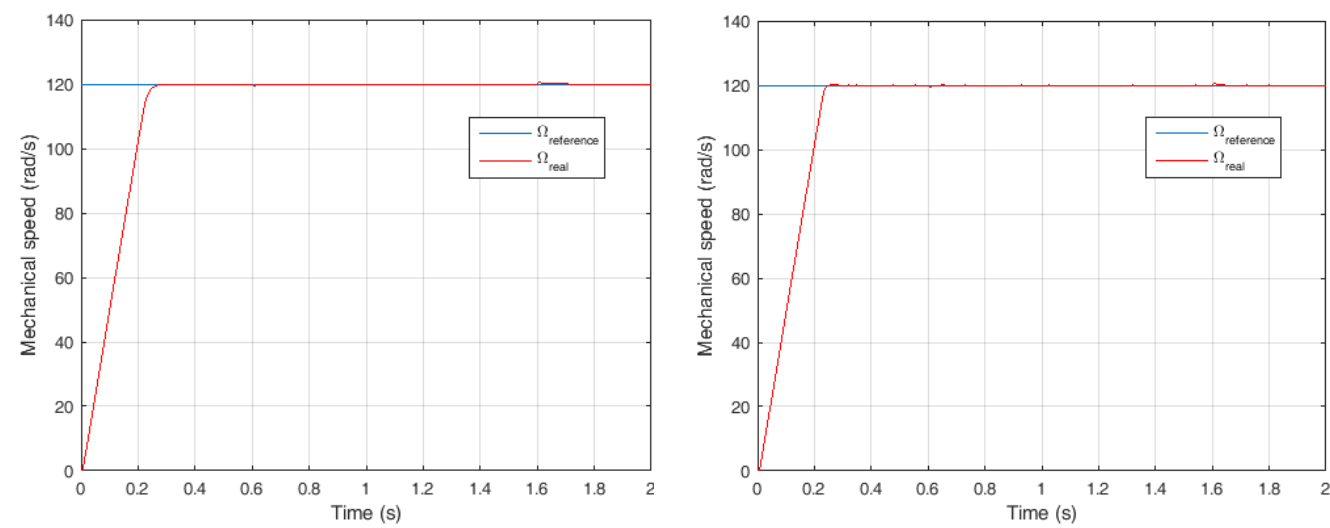

(a) Conventional DTC: mechanical speed

(b) Modified DTC: mechanical speed
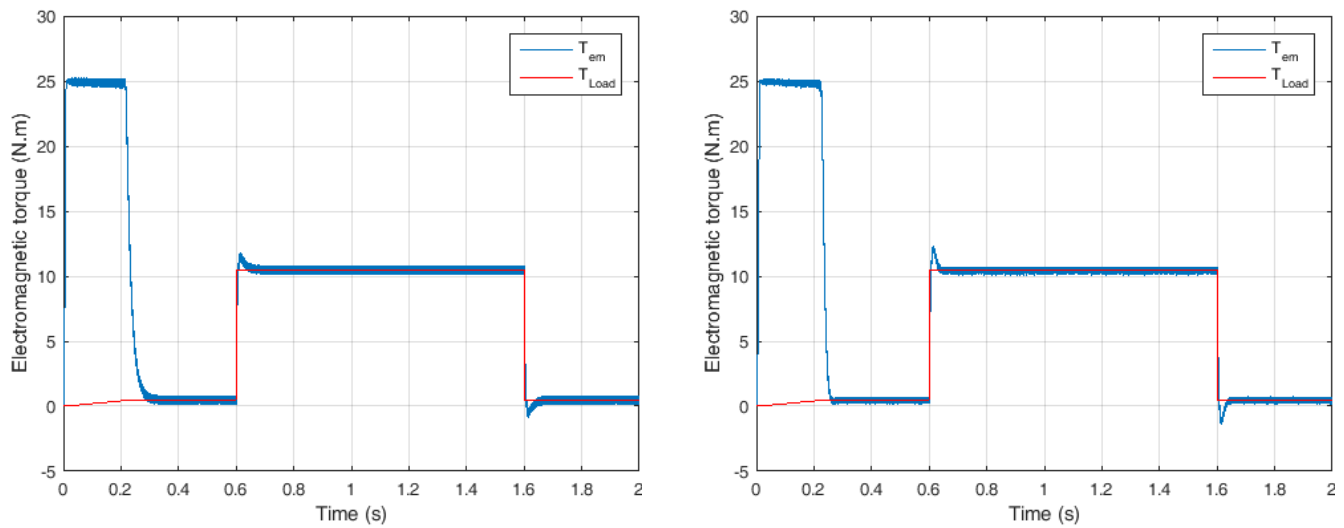

(c) Conventional DTC: electromagnetic torque

(d) Modified DTC: electromagnetic torque 

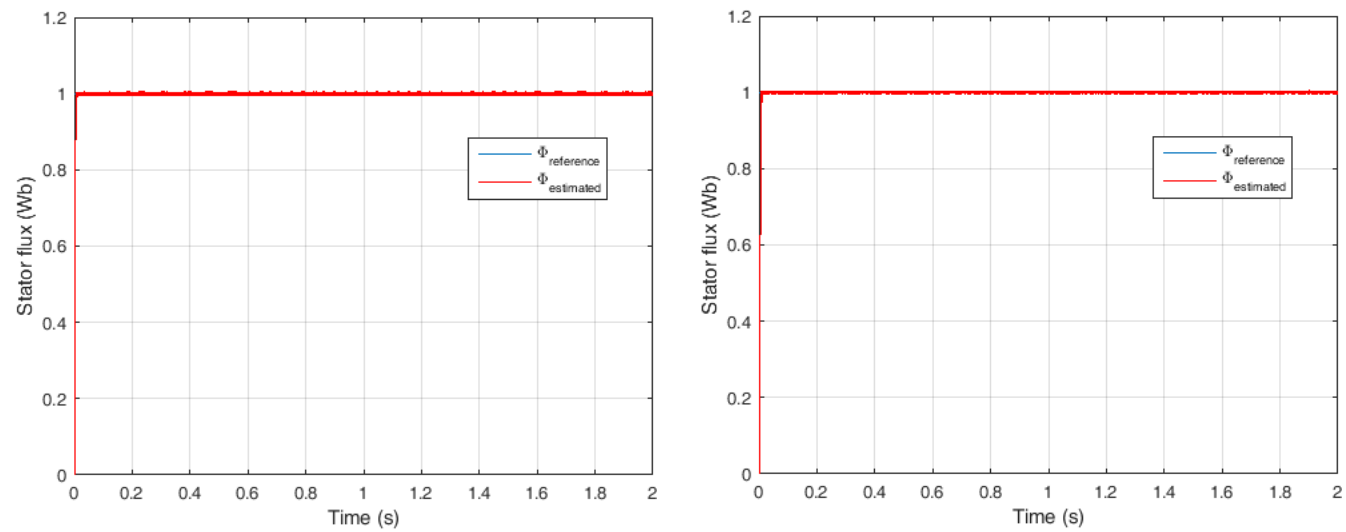

(e) Conventional DTC: stator flux

(f) Modified DTC: stator flux
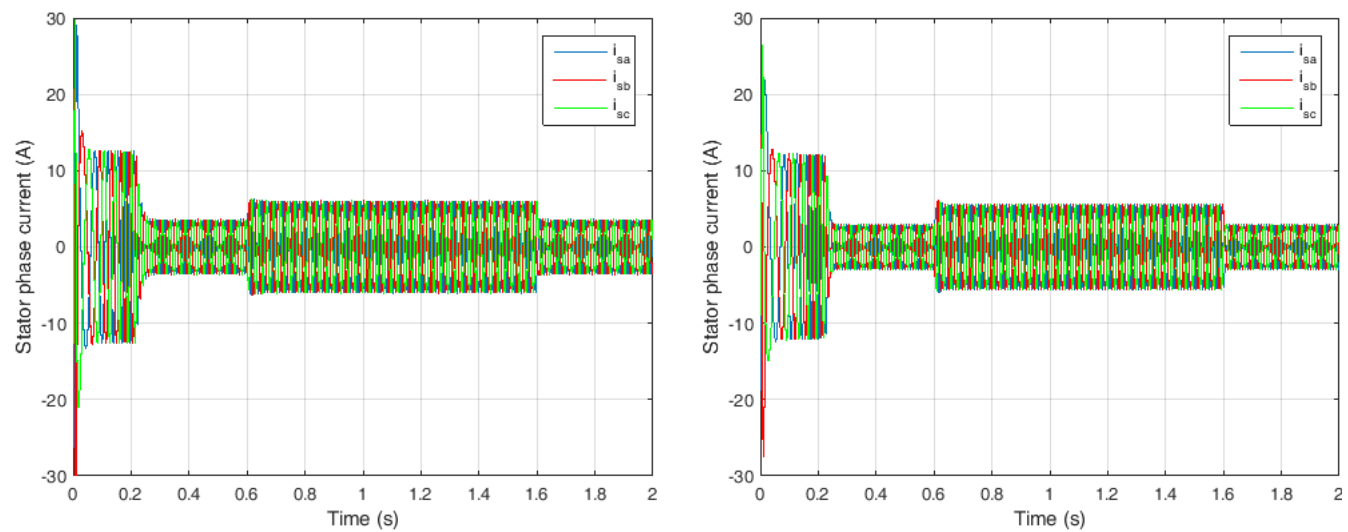

(g) Conventional DTC: stator phase currents

(h) Modified DTC: stator phase currents
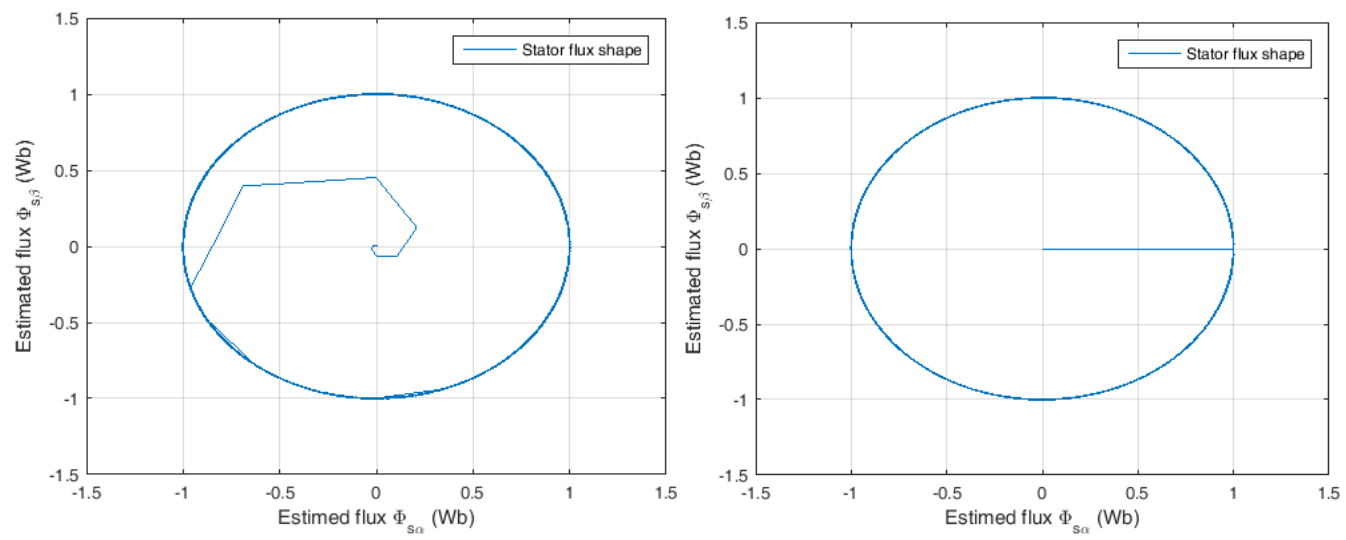

(i) Conventional DTC: flux circular trajectory

(j) Modified DTC: flux circular trajectory 

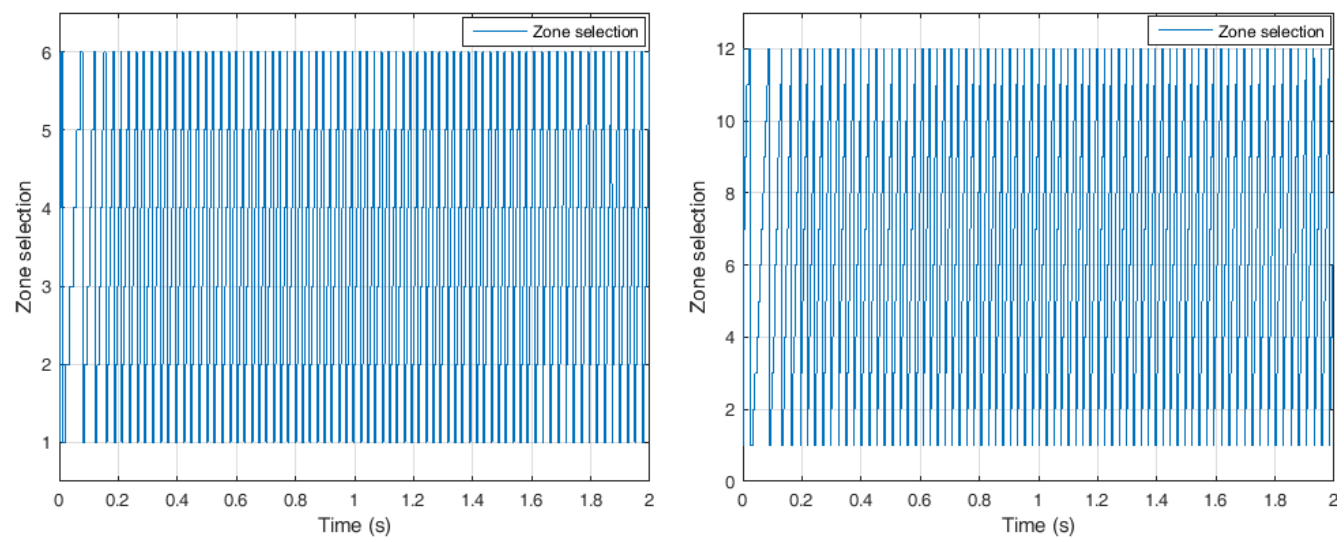

(k) Conventional DTC: zone selection

(1) Modified DTC: zone selection

Figure 17. High-speed performance improvement

The third test integrates the Luenberger observer with the fuzzy adaptation mechanism. The goal is to show the precision of the speed, the stator flux, and the state vector components observation. The reference is changing rotational direction at $t=1 \mathrm{~s}$. All the induction machine state components are displayed with their errors of observation.
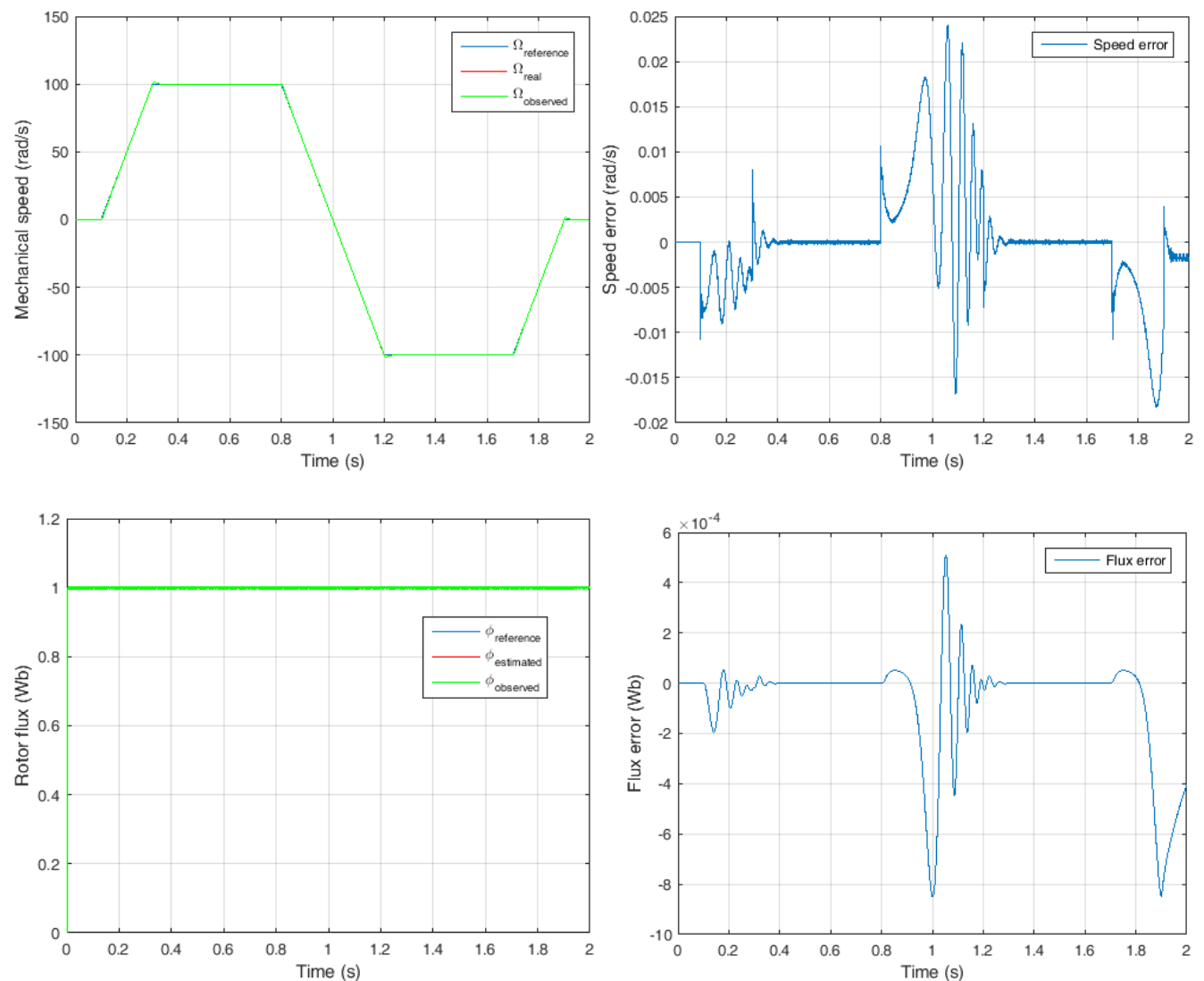

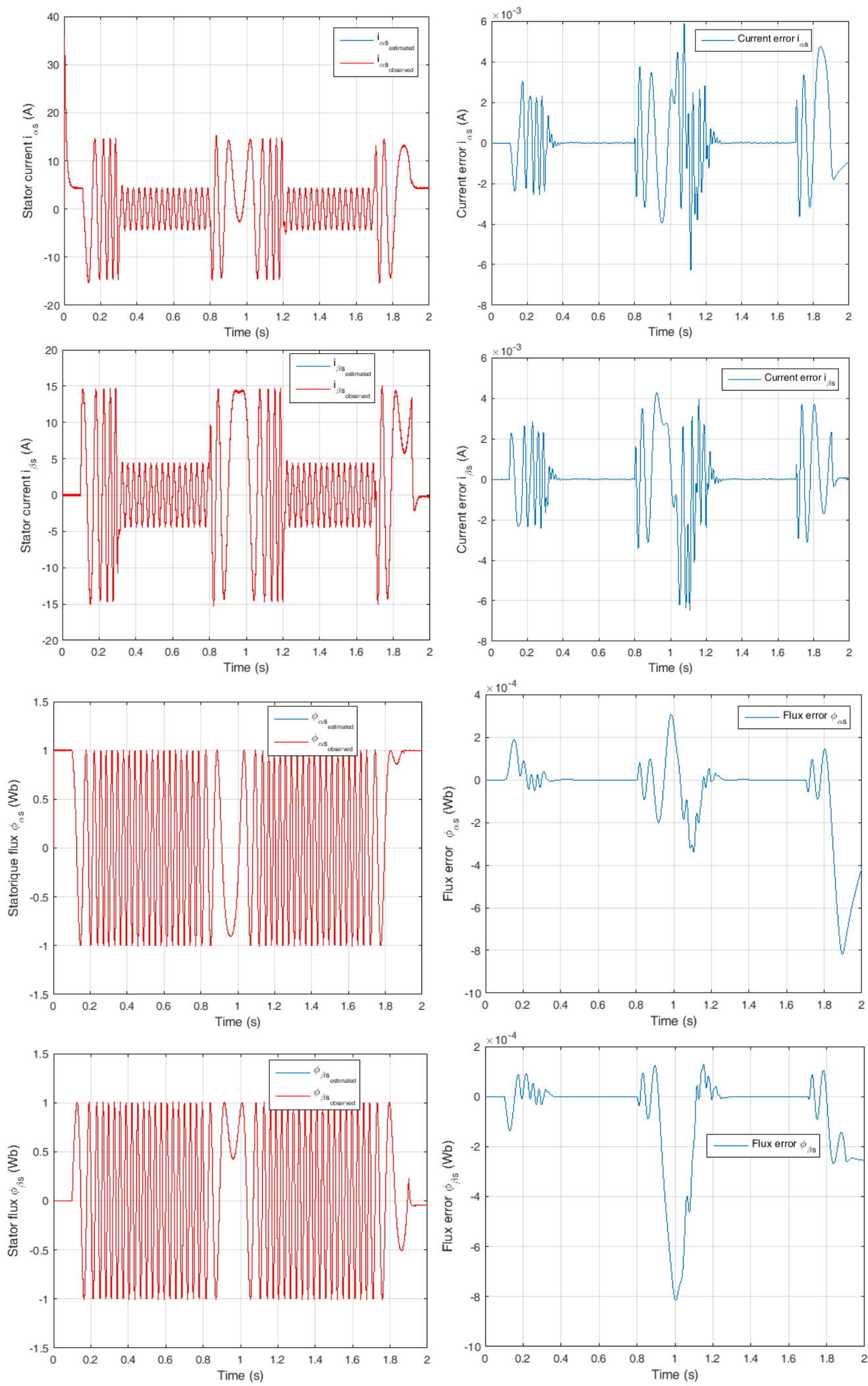

Figure 18. Sensorless modified DTC performance 
The results shown in Figure 18 demonstrate the good observation of the mechanical speed, the stator flux, and the machine state vector. The fuzzy speed controller tracks perfectly the reference. It also shows how the system can deal with reverse speed since the speed changes sense and takes negative values. The Luenberger observer is an adaptive estimator, this means that it allows finding the optimal gain matrix in order to minimize uncertainty on system state observation.

The sensorless direct torque control with fuzzy logic technique demonstrates good regulation performance and a high stability of the global system. The machine state vector is well tracked with the minimum static error. The speed error does not exceed $0.025 \mathrm{rad} / \mathrm{s}$.

\section{Conclusion}

A modified DTC for induction motor ripples reduction is designed and simulated, and its dynamic performance is studied too. The torque pulsation and the flux distortion are much better with the proposed technique. The simulated responses show that the system performance is good during the sudden load application. The flux and the torque during the steady-state are improved, with faster dynamic characteristics. The modified DTC showed reducer flux ripples, faster magnitude tracking at the starting up and better components waveform than the conventional DTC. The obtained results have confirmed the efficiency and the precision of the sensorless proposed control scheme, the key is the augmentation of number of sectors and the fuzzy algorithm in speed loop regulation that allows a good classification of the input variables. In conclusion, this technique has proved good performance dynamic operation at different speed regions.

\section{Appendix}

The rated power and parameters of the machine used in simulation are listed in the next table:

\begin{tabular}{|l|l|}
\hline Rated power & $3 \mathrm{~kW}$ \\
\hline Rated speed & $1440 \mathrm{rpm}$ \\
\hline Line voltage & $220 / 380 \mathrm{~V}$ \\
\hline Phase current & $12.5 / 7.2 \mathrm{~A}$ \\
\hline Frequency & $50 \mathrm{~Hz}$ \\
\hline Pair pole & 2 \\
\hline Stator resistance & $2.2 \Omega$ \\
\hline Rotor resistance & $2.68 \Omega$ \\
\hline Stator inductance & $0.229 \mathrm{H}$ \\
\hline Rotor inductance & $0.229 \mathrm{H}$ \\
\hline Mutual inductance & $0.217 \mathrm{H}$ \\
\hline Moment of inertia & $0.047 \mathrm{~kg} . \mathrm{m}^{2}$ \\
\hline Viscous friction coefficient & $0.004 \mathrm{~N} . \mathrm{s} / \mathrm{rad}$ \\
\hline
\end{tabular}

\section{References}

[1]. A. d. Almeida, P. Bertoldi, and W. Leonhard, Eds., Energy Efficiency Improvements in Electric Motors and Drives. Berlin Heidelberg: Springer-Verlag, 1997.

[2]. I. Boldea and S. Nasar, Vector Control of AC Drives, journal Abbreviation, Nov. 2017.

[3]. I. Takahashi and T. Noguchi, "A New Quick-Response and High-Efficiency Control Strategy of an Induction Motor," IEEE Transactions on Industry Applications, vol. IA-22, no. 5, pp. 820-827, Sep. 1986.

[4]. R. H. Kumar, A. Iqbal, and N. C. Lenin, "Review of recent advancements of direct torque control in induction motor drives - a decade of progress," IET Power Electronics, vol. 11, no. 1, pp. 1-15, 2018. 
[5]. N. H. Viet and N. Paraschiv, "An Investigation on Twelve Sectors Direct Torque Control for Induction Motors fed by Matrix Converter," in 12th International Conference on Electronics, Computers and Artificial Intelligence (ECAI), pp. 1-5, Jun. 2020.

[6]. R. Gupta, R. Kumar, and S. Bhangale, "Eighteen-sector switching strategy for torque ripple reduction of direct torque-controlled induction motor drive," International Journal of Power Electronics, vol. 3, no. 1, pp. 26-41, Jan. 2011.

[7]. D. Premkumar, T. Thamizhselvan, M. Priya, R. Carter Sb, and S. Lp, "Fuzzy AntiWindup PID Controlled Induction Motor," vol. 9, pp. 184- 189, Oct. 2019.

[8]. Z. Wu, J. Zhou, G. Zheng, T. Li, and Z. Zhu, "New Eighteen-sector Direct Torque Control Based on Duty Ratio Modulation," Journal of Physics: Conference Series, vol. 1449, p. 012033, Jan. 2020.

[9]. V. O. Nikiforov, "Observers of External Deterministic Disturbances. I. Objects with Known Parameters," Automation and Remote Control, vol. 65, no. 10, pp. 1531-1541, Oct. 2004.

[10]. Y. Zahraoui, M. Akherraz, and S. Elbadaoui, "Improvement of induction motor state observation: Extended kalman filter versus adaptive luenberger observer," WSEAS Transactions on Systems and Control, vol. 15, pp. 120-130, 2020.

[11]. X. Liu, L. Li, Z. Li, T. Fernando, and H. H. C. Iu, "Stochastic Stability Condition for the Extended Kalman Filter With Intermittent Observations," IEEE Transactions on Circuits and Systems II: Express Briefs, vol. 64, no. 3, pp. 334-338, Mar. 2017.

[12]. Y. Zahraoui and M. Akherraz, "Kalman Filtering Applied to Induction Motor State Estimation", Dynamic Data Assimilation - Beating the Uncertainties, Dinesh G. Harkut, IntechOpen, June 2020.

[13]. T. Orlowska-Kowalska and M. Dybkowski, "Stator-Current-Based MRAS Estimator for a Wide Range Speed-Sensorless Induction-Motor Drive," in IEEE Transactions on Industrial Electronics, vol. 57, no. 4, pp. 1296-1308, April 2010.

[14]. G. Kron, "Generalized theory of electrical machinery," Transactions of the American Institute of Electrical Engineers, vol. 49, no. 2, pp. 666-683, 1930.

[15]. T. Haweel, "Modeling Induction Motors," International Journal on Electrical Engineering and Informatics, vol. 4, Jun. 2012.

[16]. Y. Zahraoui, M. Akherraz, and C. Fahassa, "Induction Motor DTC Performance Improvement by Reducing Torque Ripples in Low Speed," U.P.B. Sci. Bull., Series C, vol. 81, no. 3, pp. 249-260, 2019.

[17]. A. Pal, G. D. Srivastava, and R. D. Kulkarni, "Simulation of Sensorless Speed Control of Induction Motor Using Direct Torque Control Technique Employing Five Level Torque Comparator and Twelve Sector Method," in International Conference on Nascent Technologies in Engineering (ICNTE), pp. 1-6, Jan. 2019.

[18]. N. Idris and A. Yatim, "Reduced torque ripple and constant torque switching frequency strategy for direct torque control of induction machine," in APEC. Fifteenth Annual IEEE Applied Power Electronics Conference and Exposition, vol. 1, pp. 154-161, Feb. 2000.

[19]. Y. N. Tatte and M. V. Aware, "Torque Ripple and Harmonic Current Reduction in a Three-Level Inverter-Fed Direct-Torque-Controlled Five-Phase Induction Motor," IEEE Transactions on Industrial Electronics, vol. 64, no. 7, pp. 5265-5275, Jul. 2017.

[20]. Y. Zahraoui, M. Akherraz and C. Fahassa, "Induction Motor Performance Improvement using Twelve Sectors DTC and Fuzzy Logic Speed Regulation," WSEAS transactions on systems and control, vol. 15, no 6, pp. 47-56, 2020.

[21]. A. Al-Quteimat, A. Roccaforte, and U. Schafer, "Performance improvement of direct torque control for doubly fed induction generator with 12 sector methodology," in IEEE International Conference on Renewable Energy Research and Applications (ICRERA), pp. 242-246, Nov. 2016.

[22]. N. Farah, M. H. N. Talib, N. S. Mohd Shah, Q. Abdullah, Z. Ibrahim, J. B. M. Lazi, and A. Jidin, "A Novel Self-Tuning Fuzzy Logic Controller Based Induction Motor Drive System: An Experimental Approach,” IEEE Access, vol. 7, pp. 68 172-68 184, 2019. 
[23]. Y. Bchir, S. Gdaim, and M. Abdellatif, “A Fuzzy Direct Torque Control of Induction Motor for FPGA Implementation," International Journal on Electrical Engineering and Informatics, vol. 8, pp. 851-864, Dec. 2016.

[24]. M. P. Jati, E. Purwanto, B. Sumantri, M. R. Rusli, A. Nasuha, A. Tjahjono, and T. Taufik, "A Fuzzy Supervisory Scalar Control for Matrix Converter Induction Motor Drives," International Journal on Electrical Engineering and Informatics, vol. 13, no. 1, 2021.

[25]. T. Ramesh, A. Panda, and S. Kumar, "Fuzzy Logic and Sliding-Mode Speed Control Based Direct Torque and Flux Control Scheme to Improve the Performance of an Induction Motor Drive," International Journal on Electrical Engineering and Informatics, vol. 6, pp. 155-180, Mar. 2014.

[26]. A. Ghezouani, B. Gasbaoui, and J. Ghouili, "Sliding Mode Observer-based MRAS for Sliding Mode DTC of Induction Motor: Electric Vehicle," International Journal on Electrical Engineering and Informatics, vol. 11, no. 3, pp. 580-595, 2019.

[27]. S. M. Gadoue, D. Giaouris, and J. W. Finch, "Stator current model reference adaptive systems speed estimator for regenerating-mode low-speed operation of sensorless induction motor drives," IET Electric Power Applications, vol. 7, no. 7, pp. 597-606, 2013.

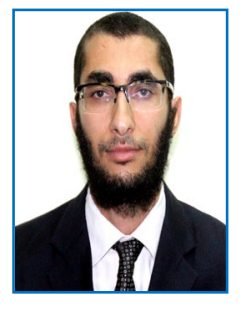

Yassine Zahraoui, he was born in Casablanca (Morocco), on September 1986. He received the Master's degree in data processing from Hassan 2 University of Casablanca (Morocco) in 2011. Currently he is a PhD student in electrical engineering in laboratory of power electronics and control (PEC) from Mohammed 5 University, Mohammadia School of Engineering. His research interests concern $\mathrm{AC}$ drives robust control, ripples reduction and sensorless control techniques for electric vehicles.

E-mail: zahraoui.yassin@gmail.com

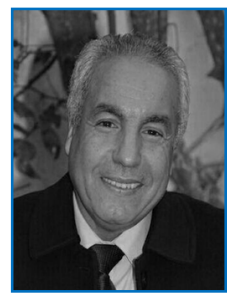

Mohamed Akherraz, he graduated from the Mohammadia School of Engineering in Rabat (Morocco). He graduated a Fulbright scholarship to pursue his post-graduate studies. He received his $\mathrm{PhD}$ in 1987 from UW, Seattle. He joined the electrical engineering department of the Mohammadia School of Engineering where he is currently a professor of power electronics and electric drives. His areas of interests are power electronics, electric drives, computer modelling of power electronics circuit and systems drives.

E-mail: akherraz@emi.ac.ma

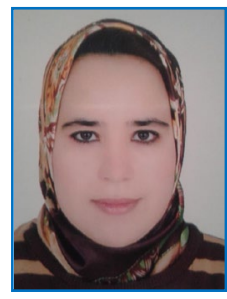

Sara Elbadaoui, she was born in Casablanca (Morocco), on September 1986. She received the Master's degree in automatic, signal processing and industrial computing from Hassan 1 University of Settat (Morocco) in 2012. Currently she is a $\mathrm{PhD}$ student in electrical engineering in laboratory of power electronics and control (PEC) from Mohammed 5 University, Mohammadia School of Engineering. Her research interests concern study and design of solar inverters with intelligent control techniques.

E-mail: elbadaouisara@gmail.com 